\title{
Protective Effect of Brazilian Propolis against Liver Damage with Cholestasis in Rats Treated with $\alpha$-Naphthylisothiocyanate
}

\author{
Tadashi Nakamura, ${ }^{1}$ Yoshiji Ohta, ${ }^{2}$ Koji Ohashi, ${ }^{3}$ Kumiko Ikeno, ${ }^{1}$ Rie Watanabe, ${ }^{1}$ \\ Kenji Tokunaga, ${ }^{4}$ and Nobuhiro Harada ${ }^{5}$ \\ ${ }^{1}$ Japan Beekeeping Co. Ltd., Gifu 500-8691, Japan \\ ${ }^{2}$ Department of Chemistry, Fujita Health University School of Medicine, Toyoake, Aichi 470-1192, Japan \\ ${ }^{3}$ Department of Clinical Biochemistry, Faculty of Medical Technology, Fujita Health University School of Health Sciences, \\ Toyoake, Aichi 470-1192, Japan \\ ${ }^{4}$ Department of Clinical Medical Technology, Kagawa Prefectural College of Health Science, Mure-cho, Kagawa 761-0123, Japan \\ ${ }^{5}$ Department of Biochemistry, Fujita Health University School of Medicine, Toyoake, Aichi 470-1192, Japan
}

Correspondence should be addressed to Yoshiji Ohta; yohta@fujita-hu.ac.jp

Received 10 January 2013; Revised 24 March 2013; Accepted 25 March 2013

Academic Editor: José Maurício Sforcin

Copyright (C) 2013 Tadashi Nakamura et al. This is an open access article distributed under the Creative Commons Attribution License, which permits unrestricted use, distribution, and reproduction in any medium, provided the original work is properly cited.

\begin{abstract}
We examined the protective effect of Brazilian propolis against liver damage with cholestasis in rats treated with $\alpha$ naphthylisothiocyanate (ANIT) in comparison with that of vitamin E (VE). Rats orally received Brazilian propolis ethanol extract (BPEE) $(25,50$, or $100 \mathrm{mg} / \mathrm{kg}), \mathrm{VE}(250 \mathrm{mg} / \mathrm{kg})$ or vehicle at $12 \mathrm{~h}$ after intraperitoneal injection of ANIT $(75 \mathrm{mg} / \mathrm{kg})$ and were killed $24 \mathrm{~h}$ after the injection. Vehicle-treated rats showed liver cell damage and cholestasis, judging from the levels of serum marker enzymes and components. The vehicle group had increased serum total cholesterol, triglyceride, phospholipid, and lipid peroxide levels, increased hepatic lipid peroxide, reduced glutathione, and ascorbic acid levels and myeloperoxidase activity, and decreased hepatic superoxide dismutase activity. BPEE $(50 \mathrm{mg} / \mathrm{kg})$ administered to ANIT-treated rats prevented liver cell damage and cholestasis and attenuated these serum and hepatic biochemical changes except hepatic ascorbic acid, although administered BPEE ( 25 or $100 \mathrm{mg} / \mathrm{kg}$ ) was less effective. VE administered to ANIT-treated rats prevented liver cell damage, but not cholestasis, and attenuated increased serum lipid peroxide level, increased hepatic lipid peroxide level and myeloperoxidase activity, and decreased hepatic superoxide dismutase activity. These results indicate that BPEE protects against ANIT-induced liver damage with cholestasis in rats more effectively than VE.
\end{abstract}

\section{Introduction}

Propolis (bee glue) is a resinous hive product collected by honeybee from various plant sources. Propolis has important pharmacological properties, and it can be used for a wide range of purposes as antiinflammatory, antioxidant, antibacterial, antiulcerous, and antitumor agents $[1,2]$. Chemically, propolis obtained from different areas of the world is constituted by $50 \%-60 \%$ of resin, $30 \%-40 \%$ of wax, $5 \%-10 \%$ of essential oils, and $5 \%$ of pollen, besides microelements [3]. Propolis contains various organic compounds such as phenols, tannins, polysaccharides, terpenes, aromatic acids, and aldehydes [1, 3-6].

Propolis collected from different areas of the world has been reported to exert a protective effect against in vivo acute liver damage in rats treated with hepatotoxicants such as carbon tetrachloride [7-12], D-galactosamine [13, 14], acetaminophen $[15,16]$, and econazole [17] through its several pharmacological actions to suppress hepatic oxidative stress associated with lipid peroxidation [7-11, 13, 16, 17] to inhibit hepatic drug-metabolizing enzymes [11, 12, 14, 15] and to ameliorate hyperlipemia $[7,12]$. However, it is still unknown 
whether propolis exerts a protective effect against in vivo acute liver damage with cholestasis in rats.

A single treatment of experimental animals with $\alpha$ naphthylisothiocyanate (ANIT) is known to induce liver damage with intrahepatic cholestasis [18-20]. This ANITinduced liver damage with cholestasis is thought to be useful for studying the mechanisms of drug-induced cholestasis, because liver damage and cholestasis resulting from the administration of certain drugs (e.g., erythromycin estolate, chlorpromazine, and others) to humans are mimicked by ANIT administration to rats [20]. The mechanisms of ANITinduced liver damage with cholestasis have been proposed but have not been entirely clarified yet. It has been suggested that hepatic reduced glutathione (GSH) contributes to the development of ANIT-induced liver damage with cholestasis by virtue of its ability to form a reversible S-conjugate of ANIT that is critical in shuttling ANIT into bile, where it is released in large and probably toxic concentrations [21]. It has also been suggested that inflammation mediated by infiltrated neutrophils contributes to the development of ANIT-induced liver damage with cholestasis in rats [21]. Furthermore, it has been shown in rats treated once with ANIT that lipid peroxidation induced by reactive oxygen species (ROS) generated via infiltrated neutrophils in the liver tissue is involved in the development of liver damage with cholestasis [22]. It has also been shown in ANITtreated rats that disruption of hepatic antioxidant defense system contributes to the development of liver damage with cholestasis $[23,24]$.

The ethanol extract of Brazilian propolis is known to possess antioxidant and anti-inflammatory properties [2531]. Vitamin E (VE) is well known to exert antioxidant and anti-inflammatory actions [32-35]. Our resent report has shown that the ethanol extract of Brazilian propolis protects against stress-induced liver damage in rats, at least in part, through its antioxidant and anti-inflammatory actions as in the case of VE [36]. Furthermore, it has been shown that VE protects against liver cell damage, but not cholestasis, in rats with a single ANIT treatment, at least in part, through its antioxidant and anti-inflammatory actions [37].

We, therefore, examined the protective effect of the ethanol extract of Brazilian green propolis against ANITinduced liver damage with cholestasis in rats in comparison with that of VE.

\section{Materials and Methods}

2.1. Materials. ANIT, bovine serum albumin, $3,3^{\prime}, 5,5^{\prime}$-tetramethylbenzidine (TMB), $p$-coumaric acid, $R R R-\alpha$ tocopherol ( $\alpha$-Toc) used for VE administration, superoxide dismutase (SOD) purified from bovine erythrocytes, and yeast glutathione reductase were purchased from Sigma (St. Louis, MO, USA); NADPH from Oriental Yeast Co. (Tokyo, Japan); chlorogenic acid from Tokyo Chemical Ind., Co. Ltd. (Tokyo, Japan); artepillin C, $L$-ascorbic acid, cinnamic acid, chrysin, N,N-dimethylformamide, $\alpha, \alpha^{\prime}$ dipyridyl, 5,5'-dithiobis(2-nitrobenzoic acid) (DTNB), ethylenediaminetetraacetic acid (EDTA), Folin-Ciocalteu reagent, gallic acid, kaempferol, quercetin, reduced glutathione (GSH), 2-thiobarbituric acid, trichloroacetic acid (TCA), standard $\alpha$-Toc and $\delta$-tocopherol used for VE determination, Tween 80 , and other chemicals from Wako Pure Chemical Ind., Ltd. (Osaka, Japan). All chemicals used were of reagent grade and were not further purified.

\subsection{Preparation of the Ethanol Extract of Brazilian Propolis.} Brazilian green propolis was collected in the area of Minas Gerais in Brazil by MN Propolis Ind., Comércio e Exportacēo, Ltda (Mogi das Cruzes, SP, Brazil). The collected propolis (Lot no. KA-02) was provided by Japan Beekeeping Co. Ltd. (Gifu, Japan). The quality of the provided propolis had been certificated as follows: artepillin C, 10.1\%; flavonoids, $41.1 \mathrm{mg} / \mathrm{g}$; and bee wax, 5.6\%. Ethanol extraction of Brazilian green propolis was conducted as follows: approximately $35 \mathrm{~g}$ of crude propolis was added to $100 \mathrm{~mL}$ of $95 \%$ ethanol and the mixture was kept at room temperature for 7 days. The final concentration of ethanol in the Brazilian propolis ethanol extract (BPEE) prepared was $80 \%$. When the prepared BPEE was completely dried at $40^{\circ} \mathrm{C}$, the content of solid components was estimated to be $13.2 \%$. The content of flavonoids in BPEE was determined according to the method of Dowd [38].

2.3. Chemical Composition Analysis. The content of total flavonoid in BPEE is expressed as that of quercetin equivalents. The content of polyphenols in BPEE was determined by the Folin-Ciocalteau colorimetric method described in the report of Ahn et al. [39]. The content of total polyphenol in BPEE is expressed as that of gallic acid equivalents. The main constituents in BPEE were analyzed by HPLC according to the method described by Izuta et al. [27] except that the mobile phase consisting of $1 \%$ acetic acid in $55 \%$ methanol was replaced by the mobile phase consisting of $1 \%$ acetic acid in $69 \%$ methanol. The HPLC was performed on a reversed-phase Shim-Pack CLC-ODS $(15 \mathrm{~cm} \times 4.5 \mathrm{~mm}$ i.d., Shimadzu, Kyoto, Japan) column with water-methanolacetic acid $(30: 70: 1, \mathrm{v} / \mathrm{v})$ as a mobile phase at a flow rate of $1 \mathrm{~mL} / \mathrm{min}$ at $40^{\circ} \mathrm{C}$. The volume of the BPEE sample injected to the column was $5 \mu \mathrm{L}$. The detection of chlorogenic acid, $p$-coumaric acid, quercetin, cinnamic acid, kaempherol, chrysin, and artepllin C in BPEE was conducted at $290 \mathrm{~nm}$ and the content of each constituent was estimated using its authentic compound.

2.4. Experimental Animals. Male Wistar rats aged six weeks were purchased from Nippon SLC Co. (Hamamatsu, Japan). The animals were housed in cages in a ventilated animal room with controlled temperature $\left(23 \pm 2^{\circ} \mathrm{C}\right)$ and relative humidity $(55 \pm 5 \%)$ with $12 \mathrm{~h}$ of light (7:00 to $19: 00)$. The animals were maintained with free access to rat chow, Oriental MF (Oriental Yeast Co., Tokyo, Japan) and tap water for one week. All animals received humane care in compliance with the Guidelines of the Management of Laboratory Animals in Fujita Health University. This animal experiment protocol was approved by the Institutional Animal Care and Use Committee. 
2.5. Experimental Groups and Administrations of ANIT, BPEE, and VE. Rats were divided into 6 groups as follows: Control group: rats not given ANIT and either BPEE or VE $(n=5)$, ANIT group: rats treated with ANIT alone $(n=$ 7), ANIT + BPEE(25) group: rats treated with ANIT and postadministered with BPEE at a dose of $25 \mathrm{mg} / \mathrm{kg}(n=$ 7), ANIT + BPEE(50) group: rats treated with ANIT and postadministered with BPEE at a dose of $50 \mathrm{mg} / \mathrm{kg}(n=$ 7), ANIT + BPEE(100) group: rats treated with ANIT and postadministered with BPEE at a dose of $100 \mathrm{mg} / \mathrm{kg}(n=$ 7), and ANIT + VE group: rats treated with ANIT and postadministered with VE $(n=7)$. ANIT treatment and postadministration of BPEE or VE were conducted as follows: ANIT was dissolved in olive oil. BPEE was diluted with 5\% Tween 80 solution and the diluted BPEE contained 6\% ethanol. Therefore, VE $(R R R-\alpha-\mathrm{Toc})$ was dissolved in $5 \%$ Tween 80 containing $6 \%$ ethanol (Tween $80-\mathrm{EtOH}$ ). In all groups with ANIT treatment, seven-week-old rats fasted for $15 \mathrm{~h}$ received an intraperitoneal (i.p.) injection of ANIT at a dose of $75 \mathrm{mg}$ per kg body weight, that is, $1 \mathrm{~mL}$ of the ANIT solution $(7.5 \mathrm{mg} / \mathrm{mL})$ per $100 \mathrm{~g}$ body weight, as described previously [22-24,37]. Age-matched rats fasted for $15 \mathrm{~h}$ in the control group received an i.p. injection of the same volume of olive oil used as vehicle. At $12 \mathrm{~h}$ after the initial i.p. injection of ANIT or vehicle (olive oil), rats in the groups with ANIT treatment were orally administered with BPEE at a dose of 25,50 , or $100 \mathrm{mg}$ of solid components present in the extract per $\mathrm{kg}$ BW or the prepared VE at a dose of $250 \mathrm{mg}$ per $\mathrm{kg}$ body weight. Namely, ANIT-treated rats received a single oral administration of $1 \mathrm{~mL}$ of the diluted BPEE solution, the VE solution, or vehicle (Tween $80-\mathrm{EtOH})$ per $100 \mathrm{~g}$ body weight. The dose of VE used in the present study was determined based on the data shown in our previous report [37]. One $\mathrm{mL}$ of Tween $80-\mathrm{EtOH}$ used as vehicle per $100 \mathrm{~g}$ body weight was orally administered to rats in Control group at the same time point. All rats used were fasted and received water ad libitum during experiments.

2.6. Sample Preparation. At $24 \mathrm{~h}$ after the initial ANIT or vehicle injection, each rat was weighed and then was sacrificed under ether anesthesia at which time blood was collected from the inferior vena cava. Serum was separated from the collected blood by centrifugation. Immediately after sacrifice, each liver was perfused with ice-cold $0.9 \% \mathrm{NaCl}$ to remove blood remaining in the tissue and then weighed after washing in an ice-cold $0.9 \% \mathrm{NaCl}$ solution and wiping on a paper filter. The collected livers and serum were stored at $-80^{\circ} \mathrm{C}$ until use.

2.7. Assays of Serum Components and Enzymes. Serum alanine aminotransferase (ALT) and aspartate aminotransferase (AST) were assayed using a commercial kit of Transaminase II-Test Wako. Serum $\gamma$-glutamyl transpeptidase ( $\gamma$-GTP) was assayed using a commercial kit of $\gamma$-GTP C-Test Wako. These enzyme activities are expressed as an international unit (IU/l). Serum total bilirubin and total bile acid were assayed using commercial kits of Bilirubin BII-Test Wako and Total bile acid-Test Wako, respectively. Total cholesterol (T-Chol), triglyceride, and phospholipid in serum were assayed using commercial kits of Cholesterol E-Test Wako, Triglyceride G-Test Wako, and Phospholipid C-Test Wako, respectively. These kits were obtained from Wako Pure Chemical Ind. Ltd. Co., Osaka, Japan. Lipid peroxide (LPO) in serum was fluorometrically measured by the thiobarbituric acid method of Yagi [40] using tetramethoxypropane as a standard. In this assay, the excitation and emission wavelengths were 515 and $553 \mathrm{~nm}$, respectively. The amount of serum LPO is expressed as that of malondialdehyde (MDA) equivalents.

2.8. Assays of Hepatic Components and Enzymes. The weight of each isolated liver was estimated using its relative weight ( $\mathrm{g} / 100 \mathrm{~g}$ body weight). The isolated liver tissue was homogenized in 9 volumes of ice-cold $50 \mathrm{mM}$ Tris- $\mathrm{HCl}$ buffer $(\mathrm{pH}$ 7.4) containing $1 \mathrm{mM}$ EDTA to prepare $10 \%$ homogenate using a Physcotron handy microhomogenizer (Microtec Co., Funabashi, Japan). The liver homogenate was used for the assays of GSH, $\alpha$-Toc, ascorbic acid, and LPO. GSH in the liver homogenate was assayed by the DTNB method of Sedlak and Lindsay [41] using GSH as a standard. $\alpha$-Toc in the liver homogenate was assayed by the HPLC method with electrochemical detection using $\delta$-tocopherol as an internal standard as described in our previous report [42]. Ascorbic acid in the liver homogenate was assayed by the $\alpha, \alpha^{\prime}$-dipyridyl method of Zannoni et al. [43]. The concentration of ascorbic acid was assayed using the standard curve of authentic $L$-ascorbic acid. LPO in the liver homogenate was spectrophotometrically assayed by the thiobarbituric acid method of Ohkawa et al. [44] using tetramethoxypropane as a standard except that $1 \mathrm{mM}$ EDTA was added to the reaction mixtures. The amount of hepatic LPO is expressed as that of MDA equivalents. Hepatic SOD was assayed using a commercial kit of SOD Assay KitWST (Doindo, Kumamoto, Japan). Hepatic catalase and Seglutathione peroxidase (Se-GSH-px) were assayed according to the methods of Bergmeyer [45] and Hochstein and Utley [46], respectively. Hepatic myeloperoxidase (MPO), an index of tissue neutrophil infiltration [47], was assayed by the method of Suzuki et al. [48]. For the assays of these enzymes, the isolated liver tissue was homogenized in 9 volumes of ice-cold 0.05 M Tris-HCl buffer (pH 7.4) using a Physcotron handy microhomogenizer. After sonication on ice for $20 \mathrm{sec}$ using a Handy Sonic model UR-20P, the homogenate was centrifuged at $4^{\circ} \mathrm{C}(10,000 \times \mathrm{g}, 20 \mathrm{~min})$, and the resultant supernatant was dialyzed against 100 volumes of the same buffer at $4^{\circ} \mathrm{C}$ for $1 \mathrm{~h}$ using a microdialysis device (molecular weight cutoff 3,500, Bio-Tec International Inc., Belleuve, WA, USA). SOD activity in the dialyzed liver tissue supernatant was determined at $37^{\circ} \mathrm{C}$ using purified erythrocyte SOD (5,000 units/mg solid) as a standard. This activity is expressed as the unit (U) of authentic purified bovine erythrocyte SOD showing activity equivalent to the determined activity. Catalase activity in the dialyzed liver tissue supernatant was measured at $37^{\circ} \mathrm{C}$ by recording hydrogen peroxide $\left(\mathrm{H}_{2} \mathrm{O}_{2}\right)$ decomposition at $240 \mathrm{~nm}$ in the reaction system $(1.0 \mathrm{~mL})$ consisting of $10 \mathrm{mM} \mathrm{H}_{2} \mathrm{O}_{2}$, an appropriate amount of the dialyzed liver supernatant, and $100 \mathrm{mM}$ phosphate buffer $(\mathrm{pH}$ 
7.0). One unit (U) of this activity is defined as the amount of enzyme decomposing $1 \mu \mathrm{mol} \mathrm{H}_{2} \mathrm{O}_{2}$ as a substrate per min. SeGSH-px activity in the dialyzed liver tissue supernatant was measured at $37^{\circ} \mathrm{C}$ by recording the decrease in absorbance at $340 \mathrm{~nm}$ following the oxidation of NADPH in the reaction system $(1.0 \mathrm{~mL})$ consisting of $2 \mathrm{mM} \mathrm{GSH}, 0.2$ unit of yeast glutathione reductase, $1 \mathrm{mM} \mathrm{NaN}_{3}$, as a catalase inhibitor, an appropriate amount of the dialyzed liver supernatant, $2 \mathrm{mM}$ $\mathrm{H}_{2} \mathrm{O}_{2}$ as a substrate, and $50 \mathrm{mM}$ phosphate buffer ( $\mathrm{pH} \mathrm{7.0)}$. One unit (U) of this activity is defined as the amount of enzyme oxidizing $1 \mu \mathrm{mol}$ NADPH per min. MPO activity in the dialyzed liver tissue supernatant was determined as follows: the dialyzed liver tissue supernatant was incubated at $60^{\circ} \mathrm{C}$ for $2 \mathrm{~h}$ to increase the recovery of MPO in liver tissues according to the method of Schierwagen et al. [49]. MPO activity in the heated liver tissue sample was assessed by measuring the hydrogen peroxide-dependent oxidation of TMB at $37^{\circ} \mathrm{C}$. TMB was dissolved in N,N-dimethylformamide. One unit (U) of this enzyme is defined as the amount of enzyme causing a change in absorbance of 1.0 per min at $655 \mathrm{~nm}$. Protein in the dialyzed liver tissue supernatant was measured using Protein Assay Rapid kit (Wako Pure Chemical Ind. Ltd. Co, Osaka, Japan). The amount of protein in the liver tissue supernatant is expressed as that of bovine serum albumin used as a standard.

2.9. Histological Examination. Liver samples were taken from the central part of the right larger lobe of ANIT-treated rats with either BPEE or VE administration and untreated control rats at $24 \mathrm{~h}$ after ANIT treatment. They were fixed with $10 \%$ formalin in phosphate buffered saline for $24 \mathrm{~h}$ and then washed with tap water, dehydrated in alcohols, and embedded in paraffin. Sections 6-7 $\mu \mathrm{m}$ thick were mounted in glass slides. Staining with hematoxylin and eosin (H-E) was performed in each slide and then histological examination was conducted under light microscopy.

2.10. Statistical Analysis. All results obtained are expressed as means \pm standard deviation (S.D.). The statistical analyses of the results were performed using a computerized statistical package (StatView). Each mean value was compared by oneway analysis of variance (ANOVA) and Bonferroni/Dunn for multiple comparisons. The significance level was set at $P<$ 0.05 .

\section{Results}

3.1. Chemical Composition. The contents of total flavonoid and total polyphenol in BPEE used in the present study were 21.3 and $69.0 \mathrm{mg} / \mathrm{g}$ of solid propolis, respectively. The contents of $p$-coumaric acid, kaempferol, chrysin, and artepillin $\mathrm{C}$ in the extract were $14.9,6.75,2.38$, and $47.8 \mathrm{mg} / \mathrm{g}$ of solid propolis, respectively. However, no chlorogenic acid, quercetin, and cinnamic acid were detected in the extract.

3.2. Effects of BPEE and VE on $f$ Liver Cell Damage and Cholestasis. Serum ALT and AST activities, indices of liver cell damage, and $\gamma$-GTP activity and total bilirubin and total bile acid concentrations, indices of biliary cell damage and cholestasis, were significantly higher in ANIT group than in Control group (Figures 1 and 2). The ANIT-induced increases in serum ALT, AST, and $\gamma$-GTP activities were significantly attenuated in ANIT + BPEE(25), ANIT + BPEE(50), and ANIT + BPEE(100) groups, while the ANITinduced increases in serum ALT and AST activities were significantly attenuated in ANIT + VE group (Figures 1(a) and 2(a)). The attenuating effect on the ANIT-induced increase in serum ALT activity in ANIT + BPEE(50) group was significantly larger than that in ANIT + BPEE(25) and ANIT + BPEE(100) groups, while the attenuating effect on ANITinduced increases in AST and $\gamma$-GTP activities in ANIT + BPEE(50) group tended to be larger than that in ANIT + BPEE25 and ANIT + BPEE(100) groups (Figures 1(a) and 2(a)). The attenuating effect on ANIT-induced increases in serum ALT and AST activities in ANIT + BPEE(50) group was almost equal to that in ANIT + VE group (Figure 1). The ANIT-induced increases in serum total bilirubin and total bile acid concentrations were significantly attenuated in ANIT + BPEE(50) group (Figures 2(b) and 2(c)). However, the ANIT-induced increases in serum total bilirubin and total bile acid concentrations were not attenuated in ANIT + BPEE(25) group (Figures 2(b) and 2(c)). Though the ANITinduced increases in serum total bilirubin concentration were significantly attenuated in ANIT + BPEE(100) group, the attenuating effect in ANIT $+\mathrm{BPEE}(100)$ group was significantly less than that in ANIT $+\operatorname{BPEE}(50)$ group $(P<$ 0.05 ) (Figures 2(b) and 2(c)). In ANIT + VE group, the ANITinduced increases in serum total bilirubin and total bile acid concentrations were not attenuated at all (Figures 2(b) and $2(\mathrm{c})$ ).

3.3. Effects of BPEE and VE on Live Histological Changes. HE-stained liver sections from Control group, ANIT group, ANIT + BPEE(50) group, and ANIT + VE group were examined for necrosis and inflammation. Control group showed little histological changes, ANIT group presented necrotic and degenerative changes with severe inflammatory cell infiltration, and ANIT + BPEE(50) and ANIT + VE groups presented clearly less necrotic and degenerative changes and less inflammatory cell infiltration (Figure 3 ). In addition, the histological change in ANIT + BPEE(50) group was similar to that in ANIT + VE group (Figures 3(c) and 3(d)).

3.4. Effects of BPEE and VE on Serum Lipid Concentrations. Serum T-Chol, triglyceride, and phospholipid concentrations were significantly higher in ANIT group than in Control group (Figure 4). In ANIT + BPEE50 group, the ANIT-induced increases in serum T-Chol, triglyceride, and phospholipid concentrations were significantly attenuated (Figure 4). However, only the ANIT-induced increase in serum triglyceride concentration was significantly attenuated in ANIT + BPEE(25) group, but no significant effects on the ANIT-induced increases in serum T-Chol, triglyceride, and phospholipid concentrations were observed in ANIT + BPEE(100) and ANIT + VE groups (Figure 4). 


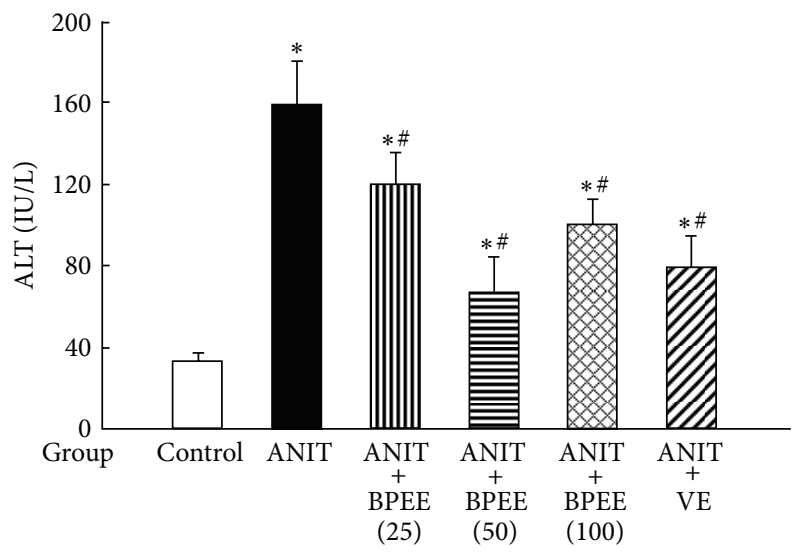

(a)

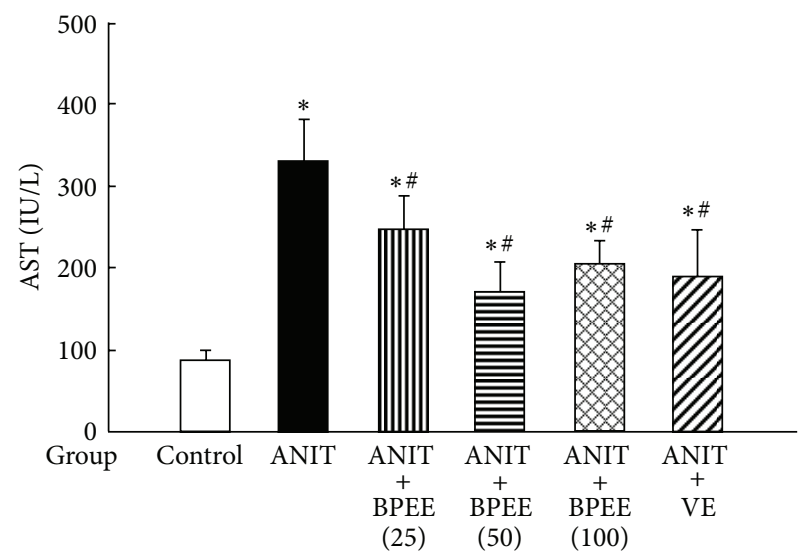

(b)

FIGURE 1: Effects of administered BPEE and VE on serum ALT (a) and AST (b) activities in ANIT-treated rats. Fasted rats in ANIT, ANIT + BPEE(25), ANIT + BPEE(50), ANIT + BPEE(100), and ANIT + VE groups were orally administered with vehicle (Tween 80-EtOH), $25 \mathrm{mg} / \mathrm{kg}$ of BPEE, $50 \mathrm{mg} / \mathrm{kg}$ of BPEE, $100 \mathrm{mg} / \mathrm{kg}$ of BPEE, and $250 \mathrm{mg} / \mathrm{kg}$ of VE, respectively, at $12 \mathrm{~h}$ after treatment with ANIT dissolved in olive oil (75 mg/kg, i.p.). Fasted rats in Control group were given olive oil and Tween 80 -EtOH used as vehicle just before and at $12 \mathrm{~h}$ after ANIT treatment, respectively. ALT and AST in serum were assayed at $24 \mathrm{~h}$ after ANIT treatment as described in Section 2 . Each value is a mean \pm S.D. ( $n=5$ for Control group; $n=7$ per each group for all groups with ANIT treatment). ${ }^{*} P<0.05$ (versus Control group); ${ }^{\#} P<0.05$ (versus ANIT group).

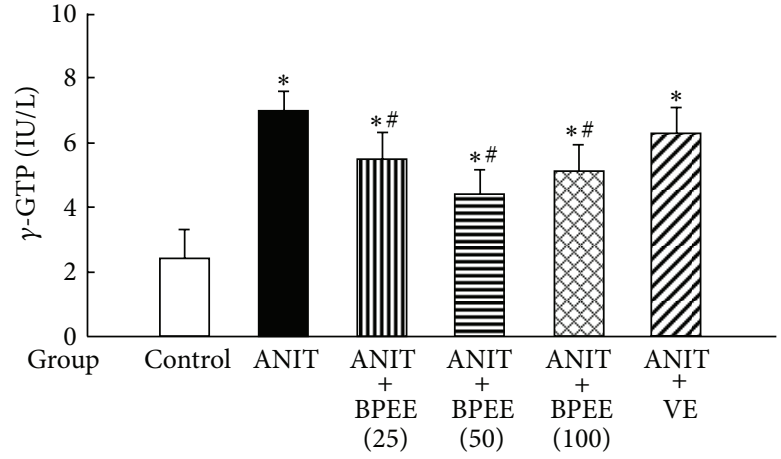

(a)

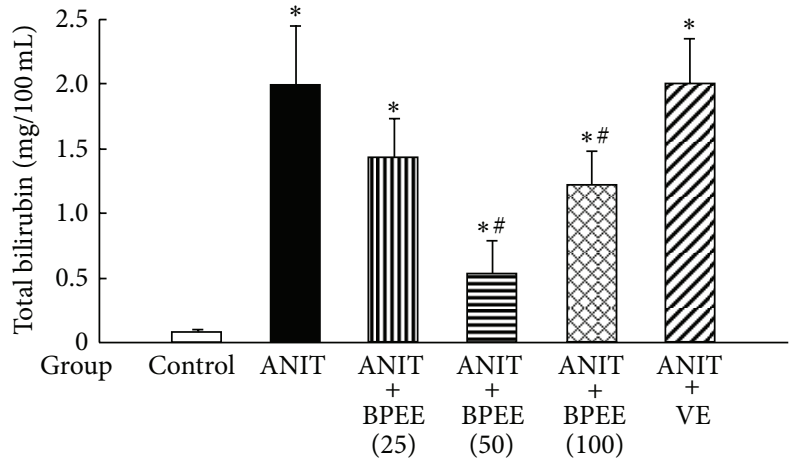

(b)

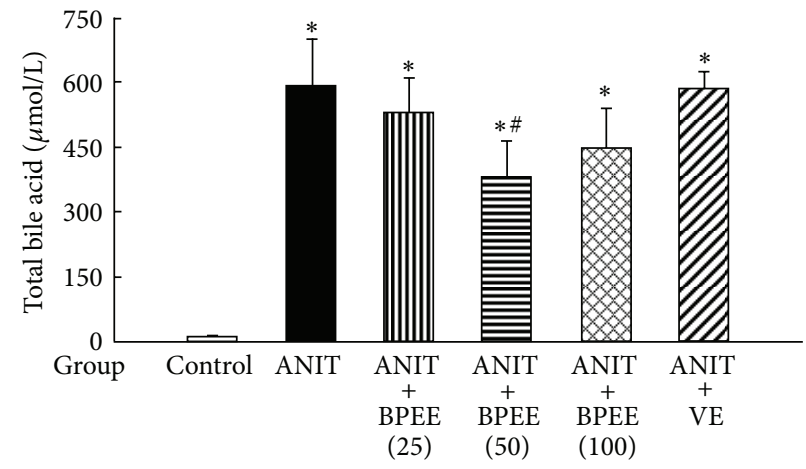

(c)

FIGURE 2: Effects of administered BPEE and VE on serum $\gamma$-GTP (a) activity and total bilirubin (b) and total bile acid (c) concentrations in ANIT-treated rats. Experimental condition and explanation are the same as described in the legend of Figure 1 except that $\gamma$-GTP, total bilirubin, and total bile acid in serum were assayed at $24 \mathrm{~h}$ after ANIT treatment as described in Section 2. Each value is a mean \pm S.D. $(n=5$ for Control group; $n=7$ per each group for all groups with ANIT treatment). ${ }^{*} P<0.05$ (versus Control group); ${ }^{\#} P<0.05$ (versus ANIT group). 


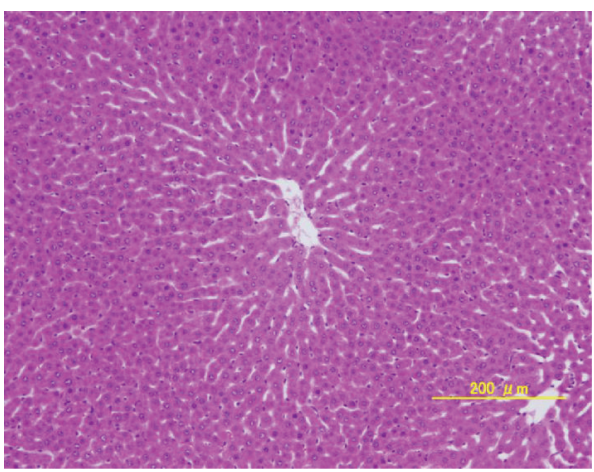

Control

(a)

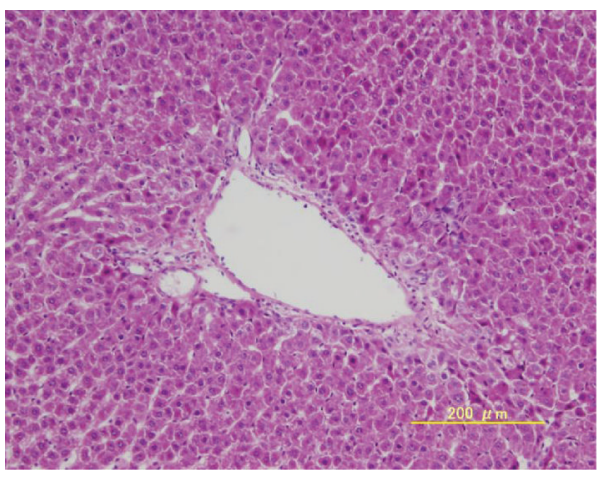

ANIT + BPEE (50)

(c)

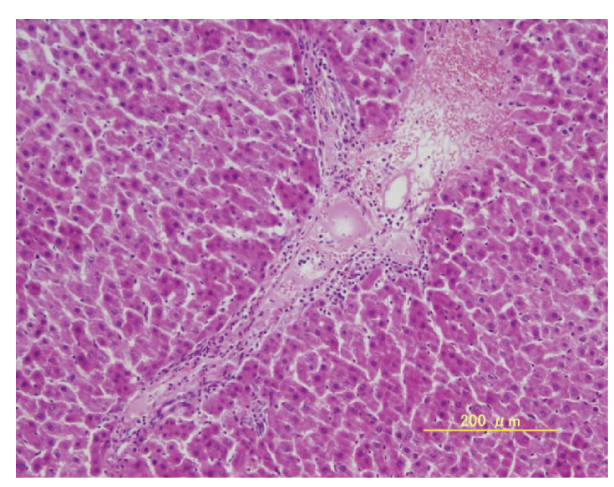

ANIT

(b)

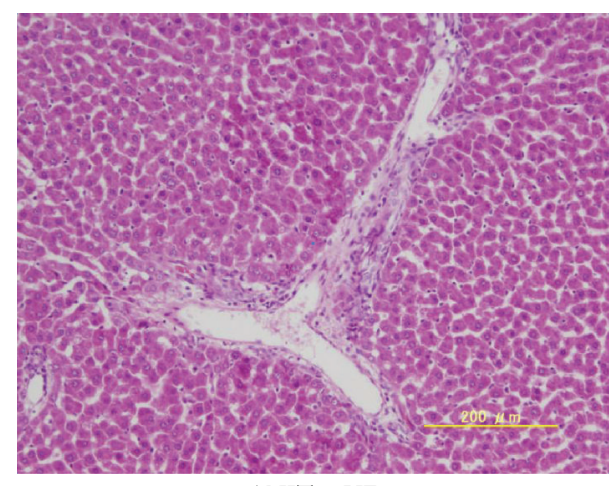

ANIT + VE

(d)

FIgURE 3: Histological Figures of liver cells from untreated control rats and ANIT-treated rats with and without either BPEE or VE. (a) Control group: little histological change was observed; (b) ANIT group: necrotic and degenerative changes with severe inflammatory cell infiltration were observed; (c) ANIT + BPEE50 group: dramatic decreases in necrotic and degenerative changes and inflammatory cell infiltration were seen; (d) ANIT + VE group: marked decreases in necrotic and degenerative changes and inflammatory cell infiltration were seen (H-E staining, original magnification $\times 100$ ).

3.5. Effects of BPEE and VE on Relative Liver Weight. ANIT group had significantly larger relative liver weight than Control group (Figure 5). In ANIT + BPEE(50) group, the ANITinduced increase in relative liver weight was significantly attenuated, while no significant effect on the increase in the relative liver weight was observed in ANIT + BPEE(25), ANIT + BPEE(100), and ANIT + VE groups (Figure 5).

3.6. Effects of BPEE and VE on Serum and Hepatic LPO Concentrations. Serum and hepatic LPO concentrations were significantly higher in ANIT group than in Control group (Figure 6). The ANIT-induced increases in serum and hepatic LPO concentrations were significantly attenuated in ANIT + BPEE(50), ANIT + BPEE(100), and ANIT + VE groups, but no significant effect on both increases was found in ANIT $+\operatorname{BPEE}(25)$ group (Figure 6). The attenuating effects on the increases in serum and hepatic LPO concentrations in ANIT $+\mathrm{BPEE}(50)$, group were similar to those in ANIT + VE group, but were significantly larger than those in ANIT + BPEE(100) group $(P<0.05)$ (Figure 6).

3.7. Effects of BPEE and VE on Hepatic Antioxidant Enzyme Activities. Hepatic SOD activity was significantly lower in
ANIT group than in Control group, although there were no significant differences in hepatic catalase and Se-GSH-px activities between both groups (Figure 7). The ANIT-induced decrease in hepatic SOD activity was significantly attenuated in ANIT + BPEE(25), ANIT + BPEE(50), ANIT + BPEE(100), and ANIT + VE groups, although ANIT + BPEE(50) group showed the most effective attenuation among the three ANIT + BPEE groups (Figure 7(a)). In addition, the hepatic SOD activity in ANIT + BPEE(50) or ANIT + BPEE(100) group was not different from that in control group (Figure 7(a)). ANIT + BPEE(25), ANIT + BPEE(50), and ANIT + VE groups had no significant effect on hepatic catalase activity but the enzyme activity was significantly reduced in ANIT + BPEE(100) group (Figure 7(b)). ANIT + BPEE(25), ANIT + BPEE(50) or ANIT + BPEE(100) group had no significant effect on hepatic Se-GSH-px activity but ANIT + VE group had a significant increase in that activity (Figure $7(\mathrm{c})$ ).

3.8. Effects of BPEE and VE on Hepatic Antioxidant Concentrations. Hepatic GSH and ascorbic acid concentrations were significantly higher in ANIT group than in Control group but there was no significant difference in hepatic $\alpha$-Toc 


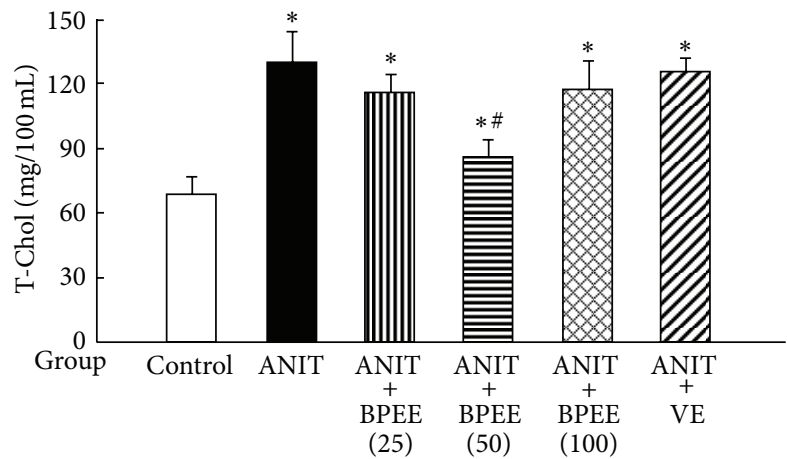

(a)

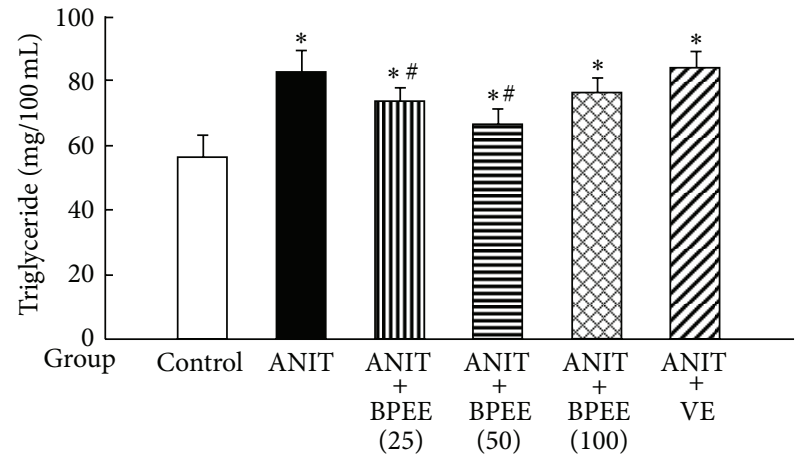

(b)

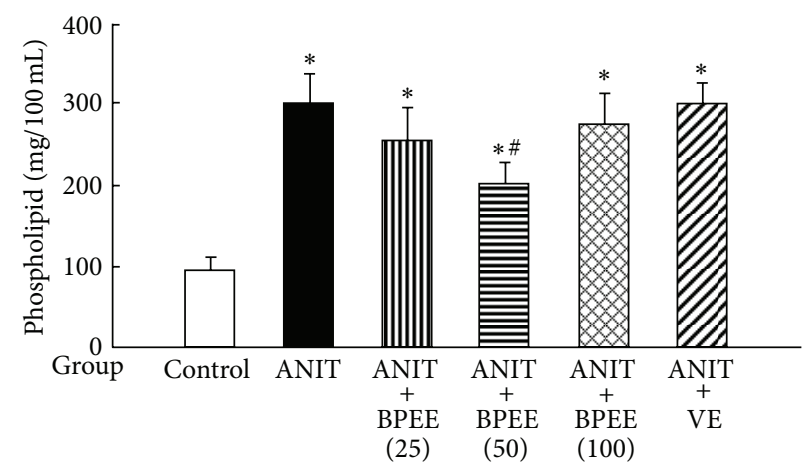

(c)

FIGURE 4: Effects of administered BPEE and VE on serum T-Chol (a), triglyceride (b), and phospholipid (c) concentrations in ANIT-treated rats. Experimental condition and explanation are the same as described in the legend of Figure 1 except that T-Chol, triglyceride, and phospholipid in serum were assayed at $24 \mathrm{~h}$ after ANIT treatment as described in Section 2. Each value is a mean \pm S.D. ( $n=5$ for Control group; $n=7$ per each group for all groups with ANIT treatment). ${ }^{*} P<0.05$ (versus Control group); ${ }^{*} P<0.05$ (versus ANIT group).

concentration between both groups (Figure 8). The ANITinduced increase in hepatic GSH concentration was significantly attenuated in ANIT + BPEE(25), ANIT + BPEE(50) or ANIT + BPEE(100) group and the attenuating effect of BPEE occurred in a dose-dependent manner, while ANIT + VE group had no significant effect on the increased hepatic GSH concentration (Figure 8(a)). ANIT + BPEE(25), ANIT + BPEE(50), ANIT + BPEE(100), and ANIT + VE groups had no significant effect on the ANIT-induced increase in hepatic ascorbic acid concentration (Figure 8(b)). ANIT + BPEE(25), ANIT + BPEE(50), and ANIT + BPEE(100) groups showed no significant effect on the hepatic $\alpha$-Toc concentration but ANIT + VE group had a significant and marked increase in the hepatic $\alpha$-Toc concentration (Figure 8(c)).

3.9. Effects of BPEE and VE on Neutrophil Infiltration. Hepatic MPO activity was significantly higher in ANIT group than in Control group (Figure 9). The ANIT-induced increase in hepatic MPO activity was significantly attenuated in ANIT + BPEE(50) and ANIT + VE groups, although neither ANIT $+\operatorname{BPEE}(25)$ group nor ANIT + BPEE(100) group had any significant effect on the increase in hepatic MPO activity (Figure 9). The attenuating effect on the ANIT-induced increase in hepatic MPO activity was significantly less in
ANIT + BPEE(50) group than in ANIT + VE group $(P<$ 0.05) (Figure 9).

\section{Discussion}

The presence of $p$-coumaric acid, kaempferol, chrysin, and artepillin C in BPEE, which was prepared by extraction of Brazilian green propolis with 95\% ethanol and used in the present study, was confirmed by the HPLC analysis used and the content of artepillin $\mathrm{C}$ was the highest among the contents of four constituents determined. This result was consistent with previous reports $[5,27,50]$.

Our previous reports have shown that rats treated once with ANIT (75 mg/kg, i.p.) have liver cell damage and cholestasis, judging from the serum levels of ALT and AST, indices of liver cell damage, and $\gamma$-GTP, total bilirubin, and total bile acid, indices of biliary cell damage and cholestasis, at $24 \mathrm{~h}$, but not at $12 \mathrm{~h}$, after the treatment [22-24, 37]. In the present study, a single oral administration of BPEE or VE to ANIT-treated rats was conducted at $12 \mathrm{~h}$ after ANIT treatment, because this delayed administration of BPEE or $\mathrm{VE}$ is thought to be useful for providing the administration effect of the extract or the vitamin on ANIT-induced liver damage with cholestasis in a condition closer to the clinical situation. When liver cell damage was evaluated from the 


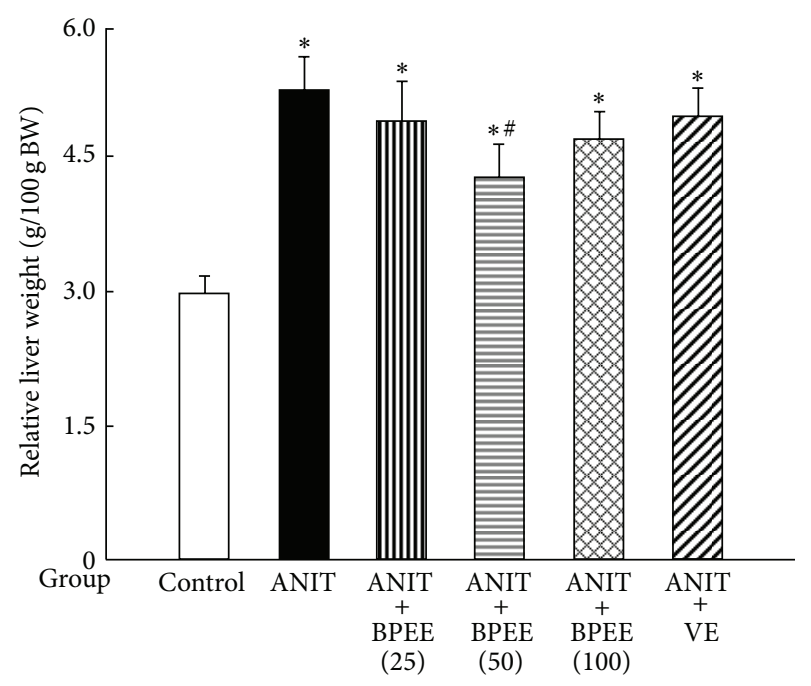

FIGURE 5: Effects of administered BPEE and VE on liver weight in ANIT-treated rats. Experimental condition and explanation are the same as described in the legend of Figure 1 except that the liver weight of each rat was estimated using its relative weight $(\mathrm{g} / 100 \mathrm{~g}$ body weight) at $24 \mathrm{~h}$ after ANIT treatment as described in Section 2. Each value is a mean \pm S.D. $(n=5$ for Control group; $n=7$ per each group for all groups with ANIT treatment). ${ }^{*} P<0.05$ (versus Control group); ${ }^{\#} P<0.05$ (versus ANIT group).

changes in serum ALT and AST activities, BPEE administered at a dose of 25,50 , or $100 \mathrm{mg} / \mathrm{kg}$ at $12 \mathrm{~h}$ after ANIT treatment was found to protect against ANIT-induced liver cell damage in rats. However, the protective effect of BPEE was higher at its dose of $50 \mathrm{mg} / \mathrm{kg}$ than at its dose of 25 or $100 \mathrm{mg} / \mathrm{kg}$, indicating that the protective effect of BPEE against ANITinduced liver cell damage is diminished at its high dose. VE $(250 \mathrm{mg} / \mathrm{kg})$ administered to ANIT-treated rats at $12 \mathrm{~h}$ after the treatment attenuated the increases in serum ALT and AST activities, as reported previously [37], and these effects were similar to those of BPEE $(50 \mathrm{mg} / \mathrm{kg})$. When the serum levels of $\gamma$-GTP, total bilirubin, and total bile acid were examined as indices of biliary damage and cholestasis, orally administered $\operatorname{BPEE}(25,50$, or $100 \mathrm{mg} / \mathrm{kg})$ was found to attenuate the ANITinduced increase in serum $\gamma$-GTP activity, although BPEE at a dose of $50 \mathrm{mg} / \mathrm{kg}$ was more effective than its dose of 25 or $100 \mathrm{mg} / \mathrm{kg}$. In addition, BPEE administered at a dose of $50 \mathrm{mg} / \mathrm{kg}$ had a larger attenuating effect on the increases in serum total bilirubin and total bile acid concentrations than its dose of 25 or $100 \mathrm{mg} / \mathrm{kg}$. The administered VE had no effect on the ANIT-induced increases in serum $\gamma$-GTP activity and total bilirubin and total bile acid concentrations, as reported previously [37]. Thus, orally administered BPEE (50 mg/kg) was found to protect against ANIT-induced liver damage with cholestasis in rats more effectively than the similarly administered VE $(250 \mathrm{mg} / \mathrm{kg})$. However, BPEE administered at a dose of $100 \mathrm{mg} / \mathrm{kg}$ was found to reduce its protective effect against ANIT-induced liver damage with cholestasis. Our recent report [36] has shown that a single oral preadministration of BPEE $(50 \mathrm{mg} / \mathrm{kg})$ to rats subjected to waterimmersion restraint stress is more effective in protecting against liver oxidative damage induced by the stress than that of BPEE $(100 \mathrm{mg} / \mathrm{kg})$. In addition, orally administered BPEE $(50 \mathrm{mg} / \mathrm{kg}$ ) was found to attenuate histological changes associated with necrosis and inflammation in liver cells observed in rats treated with ANIT alone as in the case of orally administered VE.

It is known that, in rats treated once with ANIT, increases in serum or plasma free cholesterol, cholesteryl ester, triglyceride, and phospholipid concentrations due to serum or plasma lipoprotein abnormality occur with the development of liver damage with cholestasis [51-53]. In the present study, ANIT-treated rats had increased serum TChol, triglyceride, and phospholipid concentrations at $24 \mathrm{~h}$ after the treatment and especially the treated rats had a marked increase in serum phospholipid concentration, as reported previously [51-53]. A single oral administration of $\mathrm{BPEE}(50 \mathrm{mg} / \mathrm{kg})$ caused a significant attenuation of the ANIT-induced increases in serum T-Chol, triglyceride, and phospholipid concentrations, although the similarly administered BPEE (25 or $100 \mathrm{mg} / \mathrm{kg}$ ) was less effective. By contrast, the similarly administered VE $(250 \mathrm{mg} / \mathrm{kg})$ had no significant effect on not only the increases in serum T-Chol and triglyceride concentrations, as reported previously [37], but also the increase in serum phospholipid concentration. Thus, orally administered BPEE ( $50 \mathrm{mg} / \mathrm{kg}$ ) was found to be effective in attenuating increased serum T-Chol, triglyceride, and phospholipid concentrations in ANIT-treated rats. This attenuating effect of BPEE on ANIT-induced increases in serum lipid concentrations may be associated with amelioration of serum lipoprotein abnormality, although the attenuating mechanism is unclear at present.

It has been shown in rats treated once with ANIT (75 $\mathrm{mg} / \mathrm{kg}$, i.p.) that the relative liver weight ( $\mathrm{g} / 100 \mathrm{~g}$ body weight) begins to increase before the appearance of liver damage with cholestasis and further increases after the appearance of liver damage with cholestasis [22, 54]. In the present study, a single oral administration of BPEE $(50 \mathrm{mg} / \mathrm{kg})$ to ANIT-treated rats at $12 \mathrm{~h}$ after the treatment caused a significant attenuation of the increase in relative liver weight found at $24 \mathrm{~h}$, while the similarly administered BPEE (25 or $100 \mathrm{mg} / \mathrm{kg})$ and VE $(250 \mathrm{mg} / \mathrm{kg})$ had no significant effect on the increased relative liver weight. Thus, orally administered BPEE ( $50 \mathrm{mg} / \mathrm{kg}$ ) was found to suppress hepatic hypertrophy in ANIT-treated rats. However, both the mechanism for ANIT-induced hepatic hypertrophy in rats and the mechanism by which BPEE suppresses hepatic hypertrophy in ANIT-treated rats are unclear at present.

The ethanol extract of Brazilian propolis is known to exert antioxidant action by scavenging ROS and by inhibiting lipid peroxidation [25-28]. VE is known to function as a scavenger of ROS and as a chain breaker for lipid peroxidation [32]. It has been shown that hepatic lipid peroxidation contributes to the development of liver damage with cholestasis in rats treated once with ANIT $[22,23,37,54]$. It is known that rats treated once with ANIT (75 mg/kg, i.p.) have significant increases in hepatic and serum LPO concentrations at $24 \mathrm{~h}$ after the treatment, although a significant increase in LPO concentration in the liver, but not in the serum, of ANITtreated rats occurs at $12 \mathrm{~h}$ after the treatment $[22,23,37,55]$. 


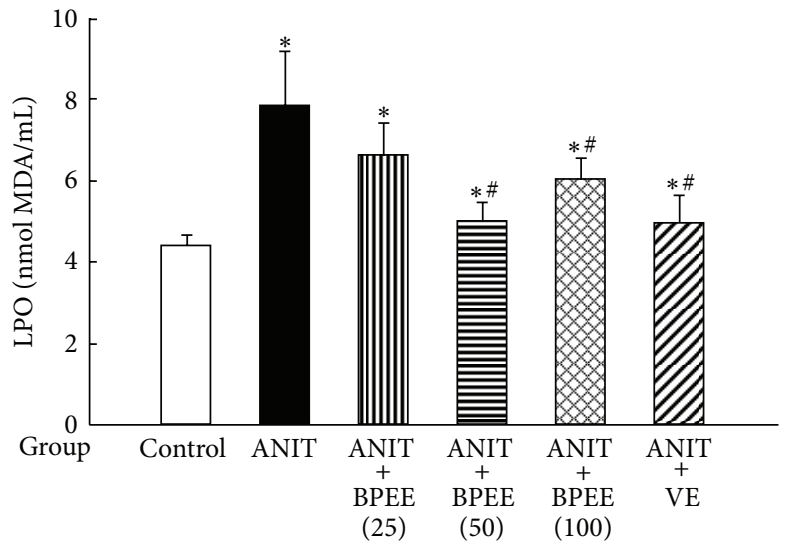

(a)

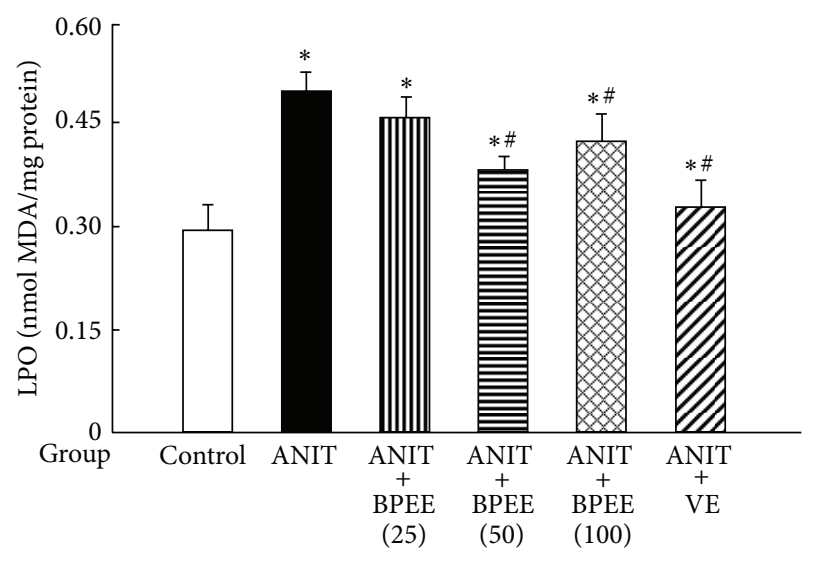

(b)

FIGURE 6: Effects of administered BPEE and VE on LPO concentrations in the serum (a) and liver (b) of ANIT-treated rats. Experimental condition and explanation are the same as described in the legend of Figure 1 except that LPO in serum and liver tissues was assayed at $24 \mathrm{~h}$ after ANIT treatment as described in Section 2. Each value is a mean \pm S.D. ( $n=5$ for Control group; $n=7$ for each group with ANIT treatment). ${ }^{*} P<0.05$ (versus Control group); ${ }^{\#} P<0.05$ (versus ANIT group).

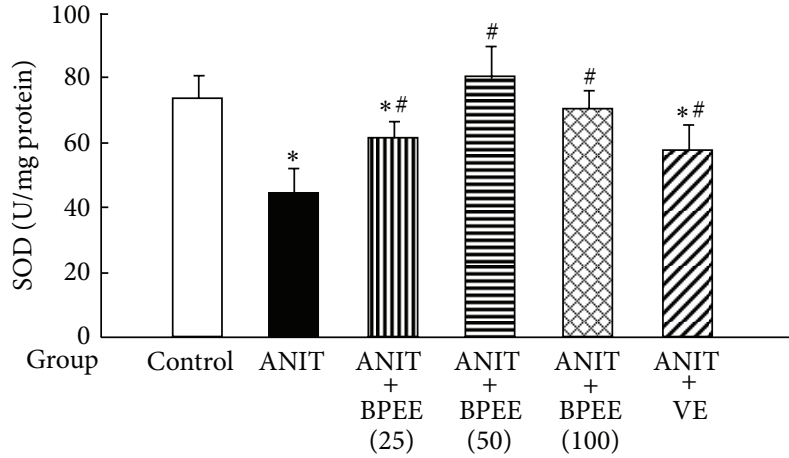

(a)

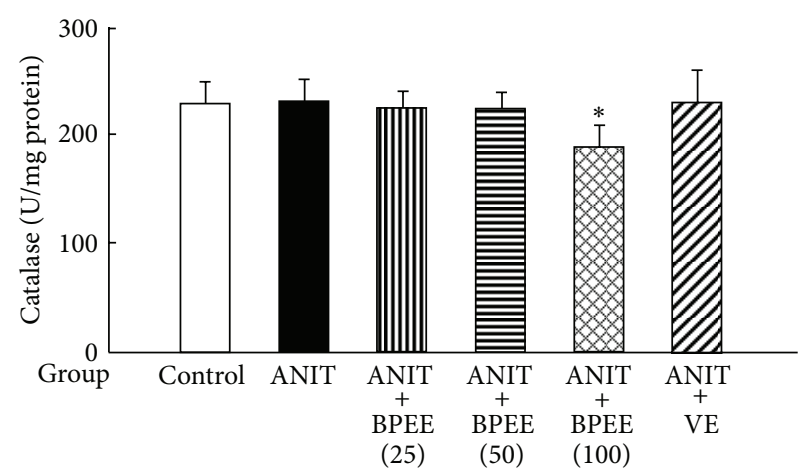

(b)

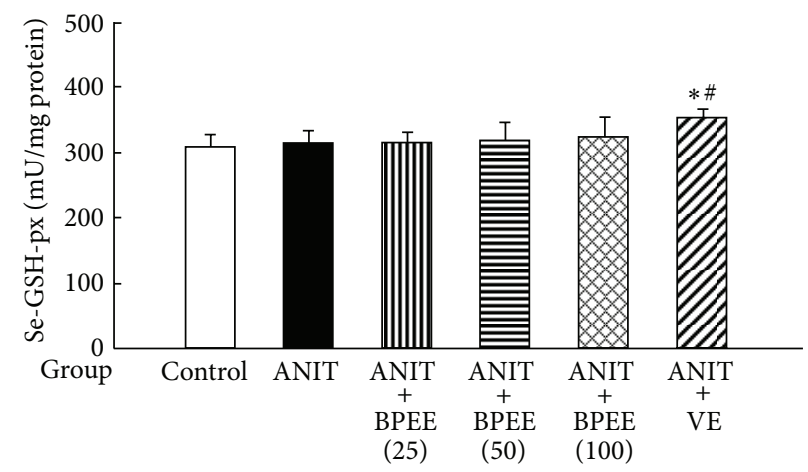

(c)

Figure 7: Effects of administered BPEE and VE on hepatic SOD (a), catalase (b), and Se-GSH-px (c) activities in ANIT-treated rats. Experimental condition and explanation are the same as described in the legend of Figure 1 except that SOD, catalase, and Se-GSH-px in liver tissues were assayed at $24 \mathrm{~h}$ after ANIT treatment as described in Section 2. Each value is a mean \pm S.D. ( $n=5$ for Control group; $n=7$ per each group for all groups with ANIT treatment). ${ }^{*} P<0.05$ (versus Control group); ${ }^{\#} P<0.05$ (versus ANIT group). 


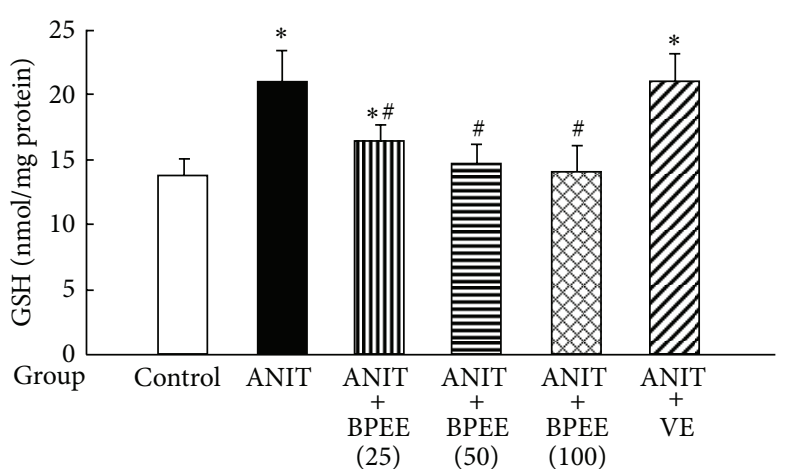

(a)

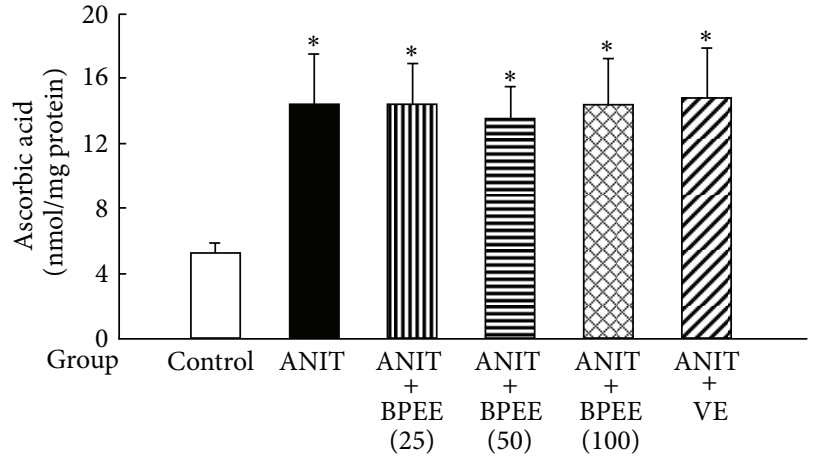

(b)

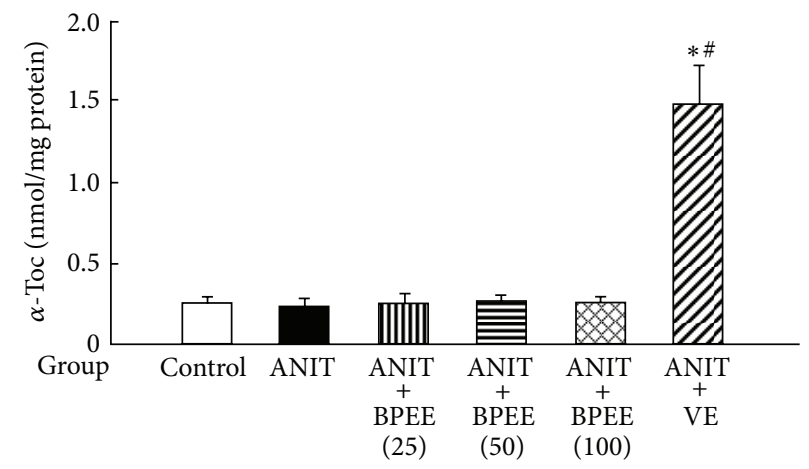

(c)

FIGURE 8: Effects of administered BPEE and VE on hepatic GSH (a), ascorbic acid (b), and $\alpha$-Toc (c) concentrations in ANIT-treated rats. Experimental condition and explanation are the same as described in the legend of Figure 1 except that GSH, ascorbic acid, and $\alpha$-Toc in liver tissues were assayed at $24 \mathrm{~h}$ after ANIT treatment as described in Section 2. Each value is a mean \pm S.D. ( $n=5$ for Control group; $n=7$ per each group for all groups with ANIT treatment). ${ }^{*} P<0.05$ (versus Control group); ${ }^{\#} P<0.05$ (versus ANIT group).

In the present study, a single oral administration of BPEE (50 or $100 \mathrm{mg} / \mathrm{kg}$ ) to ANIT-treated rats at $12 \mathrm{~h}$ after the treatment caused a significant attenuation of the increased hepatic and serum LPO concentrations found at $24 \mathrm{~h}$, although BPEE at a dose of $50 \mathrm{mg} / \mathrm{kg}$ was more effective than its dose of $100 \mathrm{mg} / \mathrm{kg}$. The similarly administered VE $(250 \mathrm{mg} / \mathrm{kg})$ caused a significant attenuation of the increased hepatic and serum LPO concentrations found at $24 \mathrm{~h}$ after ANIT treatment, as reported previously [37]. The ability of BPEE $(50 \mathrm{mg} / \mathrm{kg})$ to attenuate the ANIT-induced increases in hepatic and serum LPO concentrations was almost equal to that of VE $(250 \mathrm{mg} / \mathrm{kg})$. Therefore, it was suggested that BPEE orally administered to ANIT-treated rats could suppress lipid peroxidation occurring in the liver tissue through its antioxidant property.

It has been shown in rats treated once with ANIT $(75 \mathrm{mg} / \mathrm{kg}$, i.p.) that the hepatic SOD activity decreases at $24 \mathrm{~h}$, but not $12 \mathrm{~h}$, after the treatment, while the hepatic catalase and Se-GSH-px activities increase at $12 \mathrm{~h}$, although the increased catalase and Se-GSH-px activities are returned to the levels of untreated control rats at $24 \mathrm{~h}[23,24]$. In the present study, a single oral administration of $\operatorname{BPEE}(25,50$, or $100 \mathrm{mg} / \mathrm{kg}$ ) to ANIT-treated at $12 \mathrm{~h}$ after ANIT treatment caused a significant attenuation of the decreased hepatic SOD activity found at $24 \mathrm{~h}$ but the administered BPEE $(50 \mathrm{mg} / \mathrm{kg}$ ) exerted the highest effect and caused a complete return of the decreased hepatic SOD activity to the level of untreated control rats. The administered BPEE ( 25 or $50 \mathrm{mg} / \mathrm{kg}$ ) had no effect on the hepatic catalase activity found at $24 \mathrm{~h}$ after ANIT treatment, while the administered BPEE $(100 \mathrm{mg} / \mathrm{kg})$ caused a significant reduction of the hepatic catalase activity. All doses of BPEE had no effect on the hepatic Se-GSH-px activity found at $24 \mathrm{~h}$ after ANIT treatment. By contrast, VE $(250 \mathrm{mg} / \mathrm{kg}$ ) administered to ANIT-treated rats did not affect the hepatic catalase activity but caused a significant increase in the hepatic Se-GSH-px activity, although the administered VE partially attenuated the ANIT-induced decrease in hepatic SOD activity. Thus, orally administered BPEE was found to ameliorate disrupted hepatic enzymatic antioxidant defense system associated with SOD in ANIT-treated rats.

It has been reported that rats treated once with ANIT (75 mg/kg, i.p.) have increased hepatic GSH concentration at $24 \mathrm{~h}$ after the treatment, increased ascorbic acid concentration at 12 and $24 \mathrm{~h}$, and unchanged hepatic $\alpha$-Toc concentration at 12 and $24 \mathrm{~h}[23,24,37]$. In the present study, a single oral administration of $\operatorname{BPEE~}(25,50$, or 


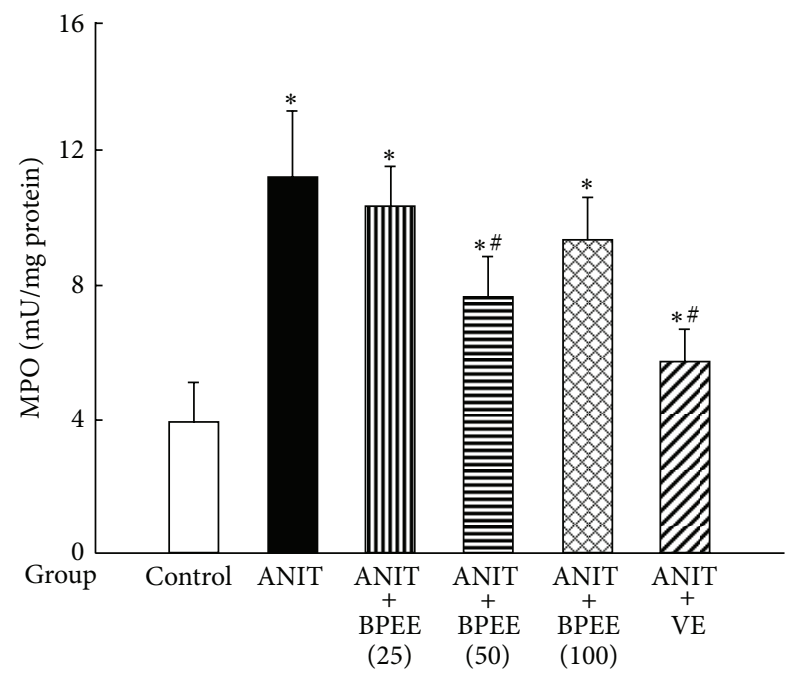

FIGURE 9: Effects of administered BPEE and VE on hepatic MPO activity in ANIT-treated rats. Experimental condition and explanation are the same as described in the legend of Figure 1 except that MPO in liver tissues was assayed at $24 \mathrm{~h}$ after ANIT treatment as described in Section 2. Each value is a mean \pm S.D. $(n=5$ for Control group; $n=7$ for each group with ANIT treatment). ${ }^{*} P<0.05$ (versus Control group); ${ }^{\sharp} P<0.05$ (versus ANIT group).

$100 \mathrm{mg} / \mathrm{kg}$ ) to ANIT-treated rats at $12 \mathrm{~h}$ after the treatment caused a significant attenuation of the increased hepatic GSH concentration found at $24 \mathrm{~h}$ but had no effect on the increased hepatic ascorbic acid concentration and the hepatic $\alpha$-Toc concentration found at $24 \mathrm{~h}$. In addition, the hepatic GSH concentration in ANIT-treated rats with administration of BPEE (50 or $100 \mathrm{mg} / \mathrm{kg}$ ) was not different from that in untreated control rats. The similarly administered VE had no effect on the increased hepatic GSH and ascorbic acid concentrations found at $24 \mathrm{~h}$ after ANIT treatment, although the administered VE caused a marked increase in the hepatic $\alpha$-Toc concentration, as reported previously [37]. It has been suggested that hepatic GSH plays a causal or permissive role in ANIT-induced liver damage with cholestasis in rats through formation of a reversible GSH conjugate of ANIT in the liver cells and transport of the GSH conjugate of ANIT into the bile, where it dissociates to free ANIT and GSH [21]. Jean et al. [56] have reported that increases in bile GSH and ANIT concentrations occur before an increase in hepatic GSH concentration in rats orally treated with ANIT $(100 \mathrm{mg} / \mathrm{kg})$. Therefore, it seems unlikely that the reduction of increased hepatic GSH concentration found at $24 \mathrm{~h}$ after ANIT treatment in rats by BPEE administered at $12 \mathrm{~h}$ affects the formation of a reversible GSH conjugate of ANIT in the liver cells. We have observed that oral administration of BPEE $(25,50$, or $100 \mathrm{mg} / \mathrm{kg})$ to ANIT-treated rats increases the concentration of nonprotein-SH including GSH in the serum in a dose-dependent manner (unpublished data). Therefore, there is a possibility that BPEE administered to ANIT-treated rats enhances the secretion of GSH from the liver tissue into the bloodstream, resulting in a reduction of the increased GSH concentration in the liver tissue.
The ethanol extract of Brazilian propolis is known to exert anti-inflammatory action by inhibiting neutrophil infiltration and the generation of ROS in activated neutrophils [2931]. VE is known to function as an anti-inflammatory agent through inhibition of the generation of ROS in activated neutrophils and neutrophil infiltration [33-35]. It has been suggested that infiltrated neutrophils in the liver tissue of rats treated with ANIT play a critical role in the development of ANIT-induced liver injury with cholestasis [21, 22]. We have shown that neutrophil infiltration into the liver tissue of rats treated once with ANIT $(75 \mathrm{mg} / \mathrm{kg}$, i.p.) increases at $12 \mathrm{~h}$ after the treatment, that is, before the appearance of liver damage with cholestasis and further increases at $24 \mathrm{~h}[22,37]$. In the present study, a single oral administration of BPEE $(50 \mathrm{mg} / \mathrm{kg})$ to ANIT-treated rats at $12 \mathrm{~h}$ after the treatment caused a significant attenuation of the increase in hepatic MPO activity, an index of tissue neutrophil infiltration [47], found at $24 \mathrm{~h}$, although the similarly administered BPEE (25 or $100 \mathrm{mg} / \mathrm{kg}$ ) had no significant effect on the increase in hepatic MPO activity. The similarly administered VE $(250 \mathrm{mg} / \mathrm{kg})$ exerted a significant attenuating effect on the increase in hepatic MPO activity, as reported previously [37], although the administered VE was more effective than BPEE administered at a dose of $50 \mathrm{mg} / \mathrm{kg}$. These results were well consistent with the above-described histological observation of liver cells. Thus, orally administered BPEE ( $50 \mathrm{mg} / \mathrm{kg}$ ) was found to inhibit neutrophil infiltration into the liver tissue of ANIT-treated rats like the case of orally administered VE. It has been shown that activated neutrophils mediate lipid peroxidation through the production of ROS via NADPH oxidase in the cells [55]. It has also been shown that MPO mediates lipid peroxidation in the presence of hydrogen peroxide and halide ions [57]. Accordingly, these findings allow us to indicate that orally administered BPEE protects against oxidative damage associated with excessive ROS generations via infiltrated neutrophils in the liver tissue of rats treated with ANIT possibly through its antiinflammatory action as in the case of orally administered VE. We have observed that BPEE in concentrations of a few $\mu \mathrm{g} / \mathrm{mL}$ causes a strong inhibition of the activity of authentic MPO isolated from human neutrophils (unpublished data). Therefore, it seems likely that orally administered BPEE contributes to its protective effect against oxidative damage caused by infiltrated neutrophils in the liver of ANIT-treated rats through inhibition of the activity of MPO in the infiltrated neutrophils.

As to the above-described decrease in hepatic SOD activity in ANIT-treated rats, it has been reported that the decrease in SOD activity in the liver of rats treated once with ANIT (75 mg/kg, i.p.) is due to a decrease in the activity of $\mathrm{Cu}, \mathrm{Zn}-\mathrm{SOD}$ present in the cytosol of liver cells [24]. $\mathrm{Cu}, \mathrm{Zn}$ $\mathrm{SOD}$ is known to be inactivated by $\mathrm{H}_{2} \mathrm{O}_{2}$ in vitro $[58,59]$. It is known that the ethanol extract of Brazilian green propolis and several compounds present in the extract can scavenge $\mathrm{H}_{2} \mathrm{O}_{2}$ in vitro [28]. As described above, it was observed that BPEE $(50 \mathrm{mg} / \mathrm{kg})$ administered to ANIT-treated rats inhibited infiltration of neutrophils to enable to produce $\mathrm{H}_{2} \mathrm{O}_{2}$ via activated NADPH oxidase into the liver tissue. Therefore, it can be thought that BPEE $(50 \mathrm{mg} / \mathrm{kg}$ ) orally administered to ANIT-treated rats attenuates the reduction of SOD activity 
in the liver tissue by inhibiting neutrophil infiltration into the tissue and/or by scavenging $\mathrm{H}_{2} \mathrm{O}_{2}$ produced by infiltrated neutrophils in the tissue.

Artepillin $\mathrm{C}$ was present as a main constituent in BPEE used in the present study. It has been reported that artepillin $\mathrm{C}$ exerts antioxidant action by scavenging ROS and by inhibiting lipid peroxidation [28, 60-62]. Therefore, it is suggested that the attenuating effect of administered BPEE on increased LPO concentration and decreased SOD activity in the liver of rats treated with ANIT could be mainly due to the antioxidant action of artepillin $\mathrm{C}$ present in the extract.

As to the main reason why BPEE administered at a dose of $100 \mathrm{mg} / \mathrm{kg}$ was less effective in protecting ANIT-induced liver damage with cholestasis than BPEE administered at a dose of $50 \mathrm{mg} / \mathrm{kg}$, the following matters could be considered: BPEE $(100 \mathrm{mg} / \mathrm{kg})$ administered to ANIT-treated rats reduced hepatic catalase activity and was less effective in inhibiting neutrophil infiltration into the liver tissue than BPEE $(50 \mathrm{mg} / \mathrm{kg})$ administered to the treated rats.

In conclusion, the results of the present study indicate that a single oral administration of BPEE to rats treated once with ANIT before the onset of apparent liver damage with cholestasis protects against liver damage with cholestasis, although this protective effect of BPEE diminishes at its high dose. The present results also suggest that the protective effect of BPEE against ANIT-induced liver damage with cholestasis could be due to the antioxidant, antiinflammatory, antihyperlipemic, and antihypertrophic actions of the extract. The orally administered BPEE $(50 \mathrm{mg} / \mathrm{kg}$ ) was found to be more effective in protecting against ANIT-induced liver damage with cholestasis than the similarly administered VE $(250 \mathrm{mg} / \mathrm{kg})$. However, further investigation is needed to clarify the exact mechanism underlining the protective effect of BPEE against liver damage with cholestasis in rats treated with ANIT.

\section{Conflict of Interests}

The authors have declared that there is no conflict of interests.

\section{Acknowledgments}

The authors thank Ms. AzusaTeruya for her excellent technical assistance and measurements of serum and hepatic enzymes and components. This work was supported by Gifu City Subsidiary for project creation "Industry-AcademicGovernment Cooperation Project Subsidiary."

\section{References}

[1] A. H. Banskota, Y. Tezuka, and S. Kadota, "Recent progress in pharmacological research of propolis," Phytotherapy Research, vol. 15, no. 7, pp. 561-571, 2001.

[2] M. Vidda-Martos, Y. Ruiz-Navajas, J. Fernández-López, and J. A. Pérez-Álvarez, "Functional properties of honey, propolis, and royal jelly," Journal of Food and Science, vol. 73, no. 9, pp. R117-R123, 2008.

[3] M. C. Marcucci, "Propolis: chemical composition, biological properties and therapeutic activity," Apidologie, vol. 26, no. 2, pp. 83-99, 1995.
[4] K. Midorikawa, A. H. Banskota, Y. Tezuka et al., "Liquid chromatography-mass spectrometry analysis of propolis," Phytochemical Analysis, vol. 12, no. 6, pp. 366-373, 2001.

[5] Y. K. Park, J. F. Paredes-Guzman, C. L. Aguiar, S. M. Alencar, and F. Y. Fujiwara, "Chemical constituents in baccharis dracunculifolia as the main botanical origin of southeastern Brazilian propolis," Journal of Agricultural and Food Chemistry, vol. 52, no. 5, pp. 1100-1103, 2004.

[6] A. Salatino, F. W. Teixeira, G. Negri, and D. Message, "Origin and chemical variation of Brazilian propolis," Evidence-Based Complementary and Alternative Medicine, vol. 2, no. 1, pp. 3338, 2005.

[7] N. Merino, R. González, A. González, and D. Remirez, "Histopathological evaluation on the effect of red propolis on liver damage induced by $\mathrm{CCl} 4$ in rats," Archives of Medical Research, vol. 27, no. 3, pp. 285-289, 1996.

[8] A. S. El-Khatib, A. M. Agha, L. G. Mahran, and M. T. Khayyal, "Prophylactic effect of aqueous propolis extract against acute experimental hepatotoxicity in vivo," Zeitschrift fur Naturforschung C, vol. 57, no. 3-4, pp. 379-385, 2002.

[9] S. Shukla, M. Bhadauria, and A. Jadon, "Effect of propolis extract on acute carbon tetrachloride induced hepatotoxicity," Indian Journal of Experimental Biology, vol. 42, no. 10, pp. $993-$ 997, 2004.

[10] M. Bhadauria, S. K. Nirala, and S. Shukla, "Duration-dependent hepatoprotective effects of propolis extract against carbon tetrachloride-induced acute liver damage in rats," Advances in Therapy, vol. 24, no. 5, pp. 1136-1145, 2007.

[11] M. Bhadauria, S. K. Nirala, and S. Shukla, "Propolis protects CYP 2E1 enzymatic activity and oxidative stress induced by carbon tetrachloride," Molecular and Cellular Biochemistry, vol. 302, no. 1-2, pp. 215-224, 2007.

[12] M. Bhadauria, S. K. Nirala, and S. Shukla, "Multiple treatment of propolis extract ameliorates carbon tetrachloride induced liver injury in rats," Food and Chemical Toxicology, vol. 46, no. 8, pp. 2703-2712, 2008.

[13] S. Rodriquez, O. Ancheta, M. E. Ramos, D. Reimirez, E. Rojas, and R. González, "Effect of Cuba red propolis on galactosamineinduced hepatitis in rats," Pharmacological Research, vol. 35, no. 1, pp. 1-4, 1997.

[14] Y. Sugimoto, T. Tarumi, Y. Kaneko et al., "Effect of propolis extract on D-galactosamine-induced hepatic injury in rats," Biological and Pharmaceutical Bulletin, vol. 22, no. 11, pp. 12371239, 1999.

[15] K. W. Seo, M. Park, Y. J. Song, S. J. Kim, and K. R. Yoon, "The protective effects of propolis on hepatic injury and its mechanism," Phytotherapy Research, vol. 17, no. 3, pp. 250-253, 2003.

[16] S. K. Nirala and M. Bhadauria, "Propolis reverses acetaminophen induced acute hepatorenal alterations: a biochemical and histopathological approach," Archives of Pharmacal Research, vol. 31, no. 4, pp. 451-461, 2008.

[17] C.-F. Liu, C.-H. Lin, C.-C. Lin et al., "Antioxidative natural product protect against econazole-induced liver injuries," Toxicology, vol. 196, no. 1-2, pp. 87-93, 2004.

[18] G. L. Plaa and B. G. Priestly, "Intrahepatic cholestasis induced by drugs and chemicals," Pharmacological Reviews, vol. 28, no. 3, pp. 207-273, 1976.

[19] H. J. Zimmerman, “Drug-induced liver disease," Drugs, vol. 16, no. 1, pp. 25-45, 1978. 
[20] D. C. Kossor, P. C. Meunier, J. A. Handler, R. S. Sozio, and R. S. Goldstein, "Temporal relationships of changes in hepatobiliary function and morphology in rats following $\alpha$-naphthylisothiocyanate (ANIT) administration," Toxicology and Applied Pharmacology, vol. 119, no. 1, pp. 108-114, 1993.

[21] R. A. Roth and L. J. Dahm, "Neutrophil- and glutathionemediated hepatotoxicity of $\alpha$ - naphthylisothiocyanate," Drug Metabolism Reviews, vol. 29, no. 1-2, pp. 153-165, 1997.

[22] M. Kongo, Y. Ohta, K. Nishida, E. Sasaki, N. Harada, and I. Ishiguro, "An association between lipid peroxidation and $\alpha$ naphthylisothiocyanate-induced liver injury in rats," Toxicology Letters, vol. 105, no. 2, pp. 103-110, 1999.

[23] Y. Ohta, M. Kongo, E. Sasaki, and N. Harada, "Change in hepatic antioxidant defense system with liver injury development in rats with a single $\alpha$-naphthylisothiocyanate intoxication," Toxicology, vol. 139, no. 3, pp. 265-275, 1999.

[24] Y. Ohta, M. Kongo, and T. Kishikawa, "Effect of melatonin on changes in hepatic antioxidant enzyme activities in rats treated with $\alpha$-naphthylisothiocyanate," Journal of Pineal Research, vol. 31, no. 4, pp. 370-377, 2001.

[25] R. Shinohara, Y. Ohta, T. Hayashi, and T. Ikeno, "Evaluation of antilipid peroxidative action of propolis ethanol extract," Phytotherapy Research, vol. 16, no. 4, pp. 340-347, 2002.

[26] F. D. Marquele, V. M. di Mambro, S. R. Georgetti, R. Casagrande, Y. M. L. Valim, and M. J. V. Fonseca, "Assessment of the antioxidant activities of Brazilian extracts of propolis alone and in topical pharmaceutical formulations," Journal of Pharmaceutical and Biomedical Analysis, vol. 39, no. 3-4, pp. 455-462, 2005.

[27] H. Izuta, Y. Narahara, M. Shimazawa, S. Mishima, S. I. Kondo, and H. Hara, "1,1-diphenyl-2-picrylhydrazyl radical scavenging activity of bee products and their constituents determined by ESR," Biological and Pharmaceutical Bulletin, vol. 32, no. 12, pp. 1947-1951, 2009.

[28] Y. Nakajima, K. Tsuruma, M. Shimazawa, S. Mishima, and H. Hara, "Comparison of bee products based on assays of antioxidant capacities," BMC Complementary and Alternative Medicine, vol. 9, article 4, 2009.

[29] L. M. C. Simões, L. E. Gregório, A. A. Da Silva Filho et al., "Effect of Brazilian green propolis on the production of reactive oxygen species by stimulated neutrophils," Journal of Ethnopharmacology, vol. 94, no. 1, pp. 59-65, 2004.

[30] N. Paulino, C. Teixeira, R. Martins et al., "Evaluation of the analgesic and anti-inflammatory effects of a Brazilian green propolis," Planta Medica, vol. 72, no. 10, pp. 899-906, 2006.

[31] K. Tan-No, T. Nakajima, T. Shoji et al., "Anti-inflammatory effect of propolis through inhibition of nitric oxide production on carrageenin-induced mouse paw edema," Biological and Pharmaceutical Bulletin, vol. 29, no. 1, pp. 96-99, 2006.

[32] D. C. Liebler, "The role of metabolism in the antioxidant function of vitamin E," Critical Reviews in Toxicology, vol. 23, no. 2, pp. 147-169, 1993.

[33] W. A. Engle, M. C. Yoder, J. L. Baurley, and P.-L. Yu, "Vitamin E decreases superoxide anion production by polymorphonuclear leukocytes," Pediatric Research, vol. 23, no. 3, pp. 245-248, 1988.

[34] T. Kanno, T. Utsumi, Y. Takehara et al., "Inhibition of neutrophil-superoxide generation by $\alpha$-tocopherol and coenzyme Q," Free Radical Research, vol. 24, no. 4, pp. 281-289, 1996.

[35] N. Yoshida, T. Yoshikawa, H. Manabe et al., "Vitamin E protects against polymorphonuclear leukocyte-dependent adhesion to endothelial cells," Journal of Leukocyte Biology, vol. 65, no. 6, pp. 757-763, 1999.
[36] T. Nakamura, Y. Ohta, K. Ohashi et al., "Protective effect of Brazilian propolis against hepatic oxidative damage in rats with water-immersion restraint stress," Phytotherapy Research, vol. 26, no. 10, pp. 1482-1489, 2012.

[37] Y. Ohta, M. Kongo-Nishimura, Y. Imai, T. Matsura, A. Kitagawa, and K. Yamada, " $\alpha$-Tocopherol protects against $\alpha$-naphthylisothiocyanate-induced hepatotoxicity in rats less effectively than melatonin," Chemico-Biological Interactions, vol. 161, no. 2, pp. 115-124, 2006.

[38] L. E. Dowd, "Spectrophotometric determination of quercetin," Analytical Chemistry, vol. 31, no. 7, pp. 1184-1187, 1959.

[39] M.-R. Ahn, S. Kumazawa, T. Hamasaka, K. S. Bang, and T. Nakayama, "Antioxidant activity and constituents of propolis collected in various areas of Korea," Journal of Agricultural and Food Chemistry, vol. 52, no. 24, pp. 7286-7292, 2004.

[40] K. Yagi, "A simple fluorometric assay for lipoperoxide in blood plasma," Biochemia Medica, vol. 15, no. 2, pp. 212-216, 1976.

[41] J. Sedlak and R. H. Lindsay, "Estimation of total, proteinbound, and nonprotein sulfhydryl groups in tissue with Ellman's reagent," Analytical Biochemistry, vol. 25, pp. 192-205, 1968.

[42] Y. Kamiya, Y. Ohta, Y. Imai, T. Arisawa, and H. Nakano, "A critical role of gastric mucosal ascorbic acid in the progression of acute gastric mucosal lesions induced by compound 48/80 in rats," World Journal of Gastroenterology, vol. 11, no. 9, pp. 13241332, 2005.

[43] V. Zannoni, M. Lynch, S. Goldstein, and P. Sato, "A rapid micromethod for the determination of ascorbic acid in plasma and tissues," Biochemia Medica, vol. 11, no. 1, pp. 41-48, 1974.

[44] H. Ohkawa, N. Ohishi, and K. Yagi, "Assay for lipid peroxides in animal tissues by thiobarbituric acid reaction," Analytical Biochemistry, vol. 95, no. 2, pp. 351-358, 1979.

[45] H. U. Bergmeyer, "Measurement of catalase activity," Biochemische Zeitschrift, vol. 327, no. 4, pp. 255-258, 1955.

[46] P. Hochstein and H. Utley, "Hydrogen peroxide detoxication by glutathione peroxidase and catalase in rat liver homogenates," Molecular Pharmacology, vol. 4, no. 6, pp. 574-579, 1968.

[47] J. E. Krawisz, P. Sharon, and W. F. Stenson, "Quantitative assay for acute intestinal inflammation based on myeloperoxidase activity. Assessment of inflammation in rat and hamster models," Gastroenterology, vol. 87, no. 6, pp. 1344-1350, 1984.

[48] K. Suzuki, H. Ota, and S. Sasagawa, "Assay method for myeloperoxidase in human polymorphonuclear leukocytes," Analytical Biochemistry, vol. 132, no. 2, pp. 345-352, 1983.

[49] C. Schierwagen, A.-C. Bylund-Fellenius, and C. Lundberg, "Improved method for quantification of tissue PMN accumulation measured by myeloperoxidase activity," Journal of Pharmacological Methods, vol. 23, no. 3, pp. 179-186, 1990.

[50] K. Yoshizumi, N. Nishioka, and T. Tsuji, "The xanthine oxidase inhibitory activity and hypouricemia effect of the propolis in rats," Yakugaku Zasshi, vol. 125, no. 3, pp. 315-321, 2005.

[51] T. Mitamura, "Alterations of high density lipoproteins in experimental intrahepatic cholestasis in the rat induced by administration of $\alpha$-naphthylisothiocyanate," Journal of Biochemistry, vol. 95, no. 1, pp. 29-36, 1984.

[52] J. W. Chisholm and P. J. Dolphin, "Abnormal lipoproteins in the ANIT-treated rat: a transient and reversible animal model of intrahepatic cholestasis," Journal of Lipid Research, vol. 37, no. 5, pp. 1086-1098, 1996.

[53] J. W. Chisholm, J. R. Paterniti, and P. J. Dolphin, "Accumulation of cholestatic lipoproteins in ANIT-treated human 
apolipoprotein A-I transgenic rats is diminished through dosedependent apolipoprotein A-I activation of LCAT,' Biochimica et Biophysica Acta, vol. 1487, no. 2-3, pp. 145-154, 2000.

[54] Y. Ohta, M. Kongo, E. Sasaki, I. Ishiguro, and N. Harada, "Protective effect of melatonin against $\alpha$-naphthylisothiocyanateinduced liver injury in rats," Journal of Pineal Research, vol. 29, no. 1, pp. 15-23, 2000.

[55] J. J. Zimmerman, W. Ciesielski, and J. Lewandoski, "Neutrophilmediated phospholipid peroxidation assessed by gas chromatography-mass spectroscopy," American Journal of Physiology, vol. 273, no. 2, pp. C653-C661, 1997.

[56] P. A. Jean, M. B. Bailie, and R. A. Roth, "1-Naphthylisothiocyanate-induced elevation of biliary glutathione," Biochemical Pharmacology, vol. 49, no. 2, pp. 197-202, 1995.

[57] T. Stelmaszynska, E. Kukovetz, G. Egger, and R. J. Schaur, "Possible involvement of myeloperoxidase in lipid peroxidation," International Journal of Biochemistry, vol. 24, no. 1, pp. 121-128, 1992.

[58] R. C. Bray, S. A. Cockle, and E. Fielden, "Reduction and inactivation of superoxide dismutase by hydrogen peroxide," Biochemical Journal, vol. 139, no. 1, pp. 43-48, 1974.

[59] E. K. Hodgson and I. Fridovich, "The interaction of bovine erythrocyte superoxide dismutase with hydrogen peroxide: inactivation of the enzyme," Biochemistry, vol. 14, no. 24, pp. 5294-5299, 1975.

[60] K. Hayashi, S. Komura, N. Isaji, N. Ohishi, and K. Yagi, "Isolation of antioxidative compounds from Brazilian propolis: 3,4dihydroxy-5-prenylcinnamic acid, a novel potent antioxidant," Chemical and Pharmaceutical Bulletin, vol. 47, no. 11, pp. 15211524, 1999.

[61] I. Nakanishi, Y. Uto, K. Ohkubo et al., "Efficient radical scavenging ability of artepillin $\mathrm{C}$, a major component of Brazilian propolis, and the mechanism," Organic and Biomolecular Chemistry, vol. 1, no. 9, pp. 1452-1454, 2003.

[62] K. Shimizu, H. Ashida, Y. Matsuura, and K. Kanazawa, "Antioxidative bioavailability of artepillin C in Brazilian propolis," Archives of Biochemistry and Biophysics, vol. 424, no. 2, pp. 181188, 2004. 


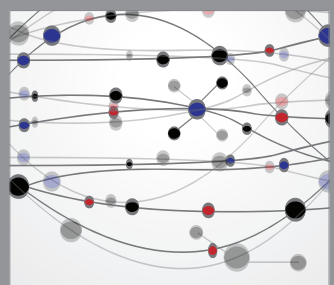

The Scientific World Journal
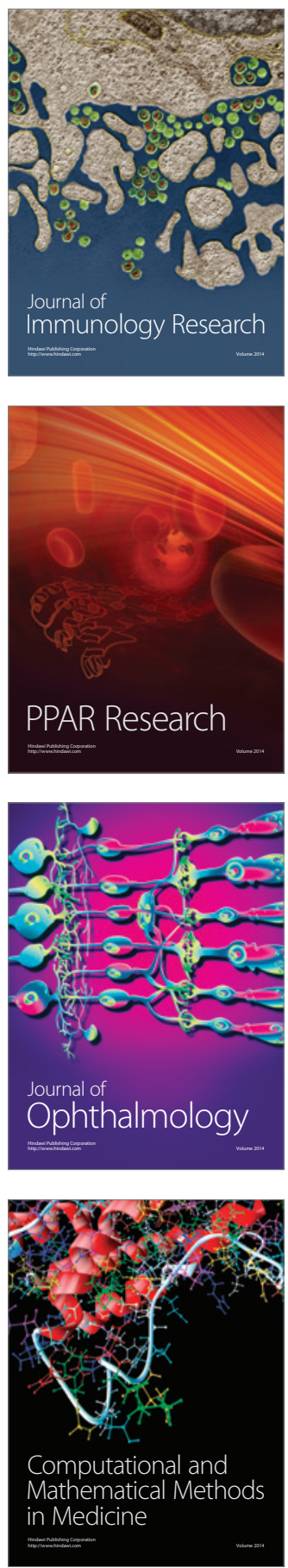

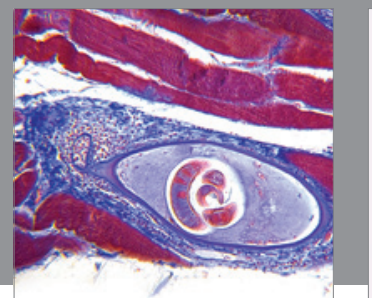

Gastroenterology

Research and Practice
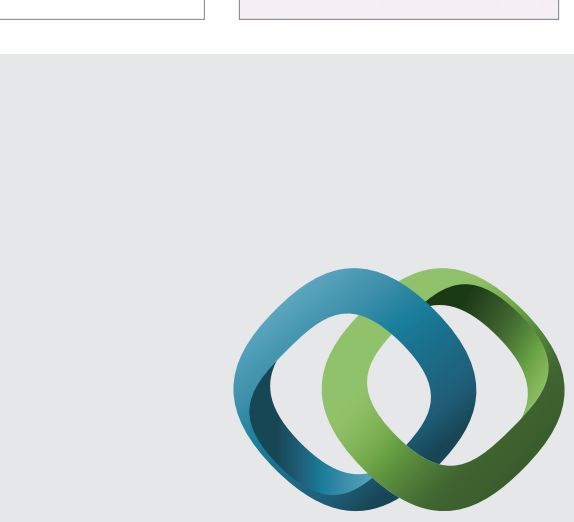

\section{Hindawi}

Submit your manuscripts at

http://www.hindawi.com
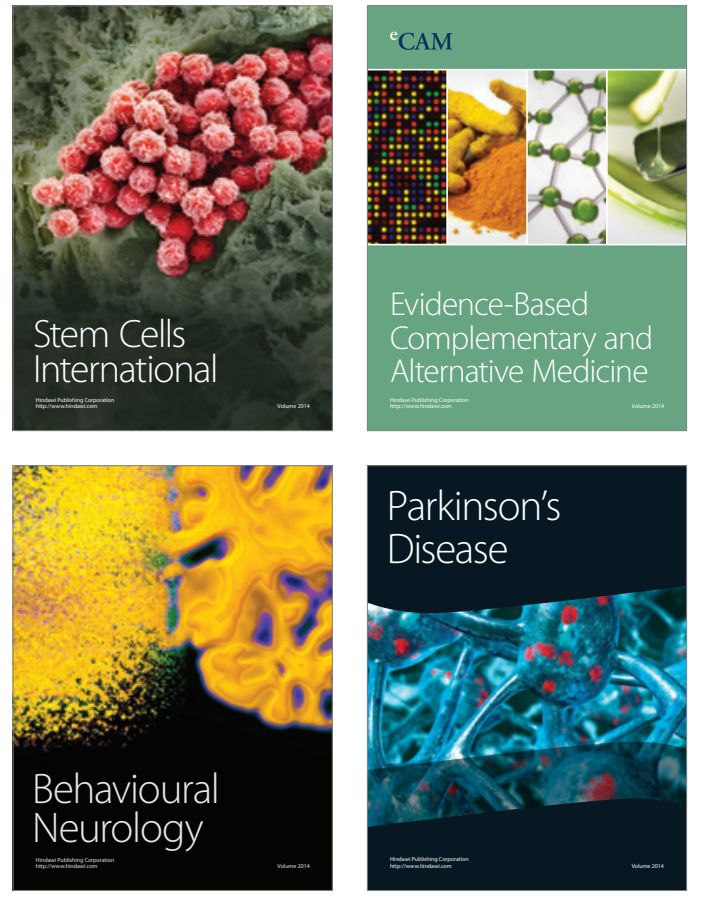
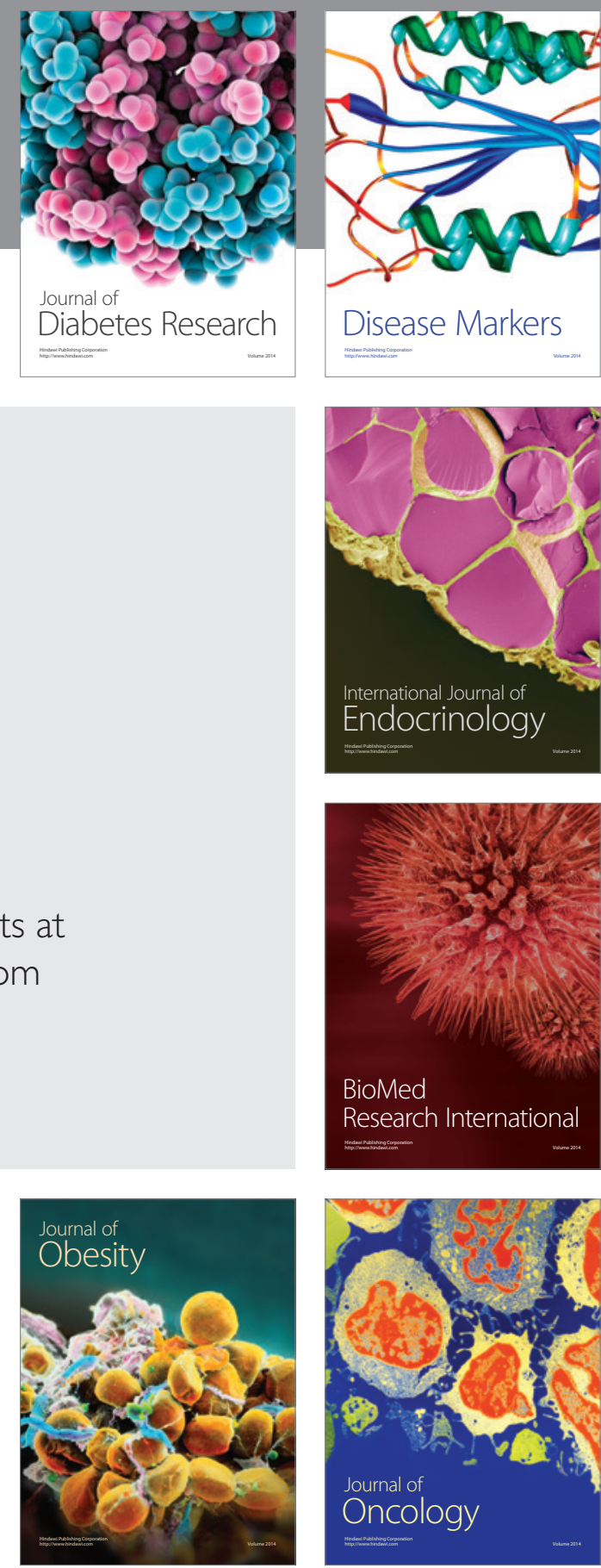

Disease Markers
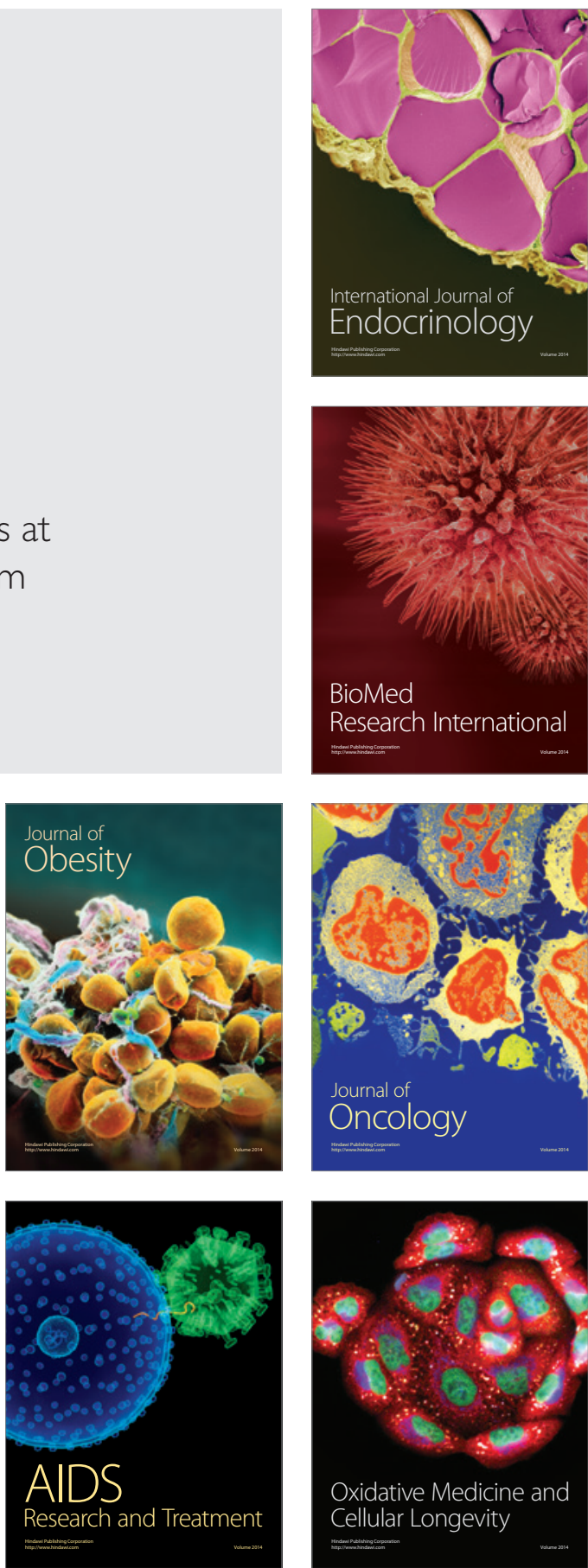